\title{
A novel fuzzy dominant goal programming for portfolio selection with systematic risk and non-systematic risk
}

\author{
Xue Deng ${ }^{1} \cdot$ Yongkang Yuan ${ }^{1}$
}

Accepted: 30 August 2021 / Published online: 22 September 2021

(c) The Author(s), under exclusive licence to Springer-Verlag GmbH Germany, part of Springer Nature 2021

\begin{abstract}
In this paper, we consider a fuzzy portfolio selection problem with systematic risk and non-systematic risk simultaneously. These two kinds of risks are measured by beta coefficient and random error variance obtained by Sharp Single Index Model. The total risk as the objective of portfolio decision is obtained by weighting the two kinds of risk. Among them, the weight of systematic risk $\lambda$ is regarded as the degree of investors' attention to system risk in economic sense. In addition, the fuzzy return and the degree of diversification are measured by triangular fuzzy number and entropy, respectively. And they are also considered the goal of investment decisions. Hence, a tri-objective portfolio is proposed in this paper. For the fuzzy objectives in the model, a goal programming method based on fuzzy dominance is proposed, which can help investors better capture the ideal point of fuzzy returns according to their risk preference. Finally, combined with the systematic impact of COVID-19 on the financial market, we make an empirical analysis based on our proposed model. The results show that the total risk will be on the high side when $\lambda$ value is too large or too small. That means paying too much or little attention to the systematic risk will lead investors to bear more risk. In addition, when investors ignore the systematic risk; that is, the $\lambda$ value is low, and investors will concentrate their funds in the same industry.
\end{abstract}

Keywords Portfolio $\cdot$ Systematic risk · Non-systematic risk $\cdot$ Sharp Single Index Model $\cdot$ Fuzzy dominant goal programming

\section{Introduction}

Due to the limitation of capital, investors must make certain trade-offs when choosing securities, which is an embodiment of resource scarcity in economy and society. In addition, we analyze investors' decisions from two extreme aspects. On the one hand, it is impossible for investors to invest only in the highest-return securities. That is because risk tolerance of investors is not enough to bear the risk. On the other hand, it is also impossible for investors to invest all their capital in risk-free securities because the available returns are too low to satisfy investors' demands. Hence, how to select securities and allocate capital is a critical problem for investors. It was not until Markowitz (Markowitz 1952) put forward modern

Yongkang Yuan

2567862702@qq.com

1 School of Mathematics, South China University of Technology, Guangzhou 510640, China portfolio theory (MPT) that the problem was solved by quantitative method for the first time. But some doubts still exist in mean-variance model (MV model) as a principal model in MPT. (1) Mean-variance model cannot provide an adjustable investment scheme in multi-periods. (2) It is found that the result output from MV model is extreme, which does not conform to the principle of investment diversification. (3) There is a doubt that whether the variance is an appropriate measure of risk. Therefore, portfolio selection is still a hot research issue.

Previous research (Liesiö et al. 2020; Soumik 2019) on portfolio was conducted in a random frame. Because the financial market is full of uncertainty, the return of securities shows a random walk trend. Therefore, scholars always regard the securities returns as random variables. Sak and Başoğlu (2017) studied the simulation of loss probability and conditional excess of linear portfolio. They proved that the robustness of the estimator could be improved by reducing the effective dimension and nonsmoothness of the integrand. Shen (2015) concerned a 
mean-variance portfolio selection problem in a complete market with unbounded random coefficients. He proved the uniqueness and existence of solutions for two backward stochastic differential equations with unbounded coefficients and derived explicit expressions of efficient portfolio and efficient frontier in a Markov model with bounded interest rates and unbounded market risk prices.

However, in the field of portfolio, it seems a more realistic problem to explore the most satisfactory portfolio from the perspective of investors than to study the optimal portfolio decision. To some extent, the random portfolio models ignore the subjective factors. Additionally, due to the lack of historical data of some newly listed companies, it is very difficult for investors to capture the random distribution of the returns of such securities. For this kind of securities investment, investors tend to refer to the performance of securities in the same industry and evaluate the returns of new listed companies subjectively. Hence, in actual investment, investors prefer to make investment decisions based on historical data and their own subjective experience. Fuzziness whose concept was proposed by Zadeh (1965) could better describe the subjectivity of investment. Referring to probability theory, possibility theory put forward by Zadeh (1978) supported the theoretical research of fuzzy numbers. Dubois and Prade (1988) defined the mean of fuzzy interval number and verified the mean of the sum of two fuzzy numbers was equal to the sum of their respective mean. Carlsson and Fullér (2001) defined possibilistic variance and covariance of fuzzy numbers. Gradually, scholars (Watada 1997; Tanaka and Guo 1999; Liagkouras and Metaxiotis 2018) began to study fuzzy portfolio instead of random portfolio. They used possibilistic mean and possibilistic variance to replace mean and variance in traditional MV model.

With the maturity of fuzzy theory, its application in the field of multi-attribute decision making is gradually emerging, especially in portfolio selection. Lv et al. (2021) presented an intelligent predictive maintenance system for multi-granularity faults of production equipment based on the Ada Belief-BP (backpropagation) neural network and the fuzzy decision making. That has overcome the deficiency of traditional research which fails to distinguish fault severity. Meng et al. (2021) studied decision making with dual hesitant fuzzy preference relations (DHFPRs) and provided a new group decision-making (GDM) method based on a series of built optimization models. A fuzzy multi-criteria decision-making framework is established by Gao et al. (2021) involving the intuitionistic fuzzy sets, score function, linear weighting method, prospect theory and analytical network process.

In the process of investment decision making, randomness and fuzziness are important uncertainties affecting the final decision making. Given the inaccuracy of certain precision formulas proposed in previous studies for the variance of a triangular fuzzy random variable (FRV), Chen et al. (2016) presented the detailed process of calculating precision variance formulas and discussed several properties of the expectation and variance of triangular FRVs. Hao et al. (2008) presented a method to calculate precision formulas of an FRV that can design algorithms that solved fuzzy random programming and handled fuzzy random optimization problems. Hose and Hanss (2021) proposed a novel imprecise probability-to-possibility transformation. This method unified many results in quantitative possibility theory concerning information modeling, data analysis, and the construction of joint distributions.

Combining subjective factors and objective factors in investment process, random fuzzy portfolio models were popular in recent years. Qin (2017) employed random fuzzy variable to describe the stochastic return on individual securities with ambiguous information and formulated mean-absolute deviation portfolio optimization models. Sadati and Nematian (2013) considered the problem to maximize the degree of both possibility and necessity so that the objective function values satisfy the fuzzy goals. Huang (2007) solved the portfolio selection problem when security returns contain both randomness and fuzziness. He reduced the computational work and sped up the process of solution compared with the random fuzzy simulation proposed in his previous algorithm. A compromise approach based on genetic algorithm was designed by $\mathrm{Li}$ and $\mathrm{Xu}$ (2013) to solve multi-objective portfolio selection model with fuzzy random returns.

In the process of investment decision making, in addition to return as a factor that must be considered, risk as a factor that makes investors uneasy must also be considered. In traditional MV model, variance is used to measure risk. Chen and Gerlach (2013) extended the univariate twosided Weibull distribution to forecast financial tail risk. Brandtner et al. (2020) conducted a decision-theoretic analysis of convex shortfall risk measures regarding their flexibility to represent subjective risk aversion and discussed the implications for the choice of optimal portfolios. Farhad et al. (2013) proposed a robust optimization approach for generating non-dominated robust solutions for multi-objective linear programming problems with imprecise coefficients in the objective functions and constraints. However, most of previous studies did not distinguish between systematic and non-systematic risks. Even if they distinguished the two risks, they only studied the impact of one of the risks on the portfolio. Few studies have considered the joint effects of both systematic and non-systematic risks on portfolio.

As mentioned before, the output of traditional MV model is prone to extreme values. Some scholars are trying 
to find an index to measure the degree of diversification to ensure the diversification of investment. In recent years, the information entropy method need less calculation, which can be used to compare the dispersion degree of different assets. Shannon (1948) referred to the viewpoint of thermodynamics and called the average amount of information without redundancy information entropy. Then, some scholars began to study the application of different entropy in portfolio and compare their performance in portfolio. For example, Philippatos and Wilson (1972) and Cheng and Wolverton (2001) studied the stochastic entropy in portfolio problems. Huang (2008) applied fuzzy entropy to portfolio. Hybrid entropy was put forward as a novel diversification measurement by $\mathrm{Xu}$ et al. (2011). Mehmet and Osman (2018) compared Shannon entropy with GiniSimpson entropy and pointed out that the latter performed better in portfolio.

In the portfolio selection problem, investors need to consider a number of mutually restricted objectives. The traditional linear programming method cannot deal with this kind of problem. In addition, it is impossible for investors to achieve the expected results on every objective. Based on this, goal programming is used to solve the multi-objective portfolio selection problem. It takes minimizing the "sum" of the distances between the objective functions and the ideal values as the final decision criterion. Gupta et al. (2019) used polynomial goal programming approach to solved portfolio model considering entropy and higher moments in intuitionistic fuzzy environment. Aouni et al. (2014) summarized different kinds of goal programming methods applied in the portfolio selection problem. Wang (2018) used fuzzy preference relations and goal programming approach to derive interval weights in analytic form.

In our paper, the risk is discussed in random environment. By Sharp Single Index Model, risk is divided into systematic risk and non-systematic risk. Additionally, we fuzzify the securities return, which reflects investors' subjective anticipation to future returns. After considering Shannon entropy, a hybrid tri-objective model including a fuzzy objective function is proposed. Then we put forward a novel fuzzy dominant goal programming to solve our proposed model. By a numerical example, the importance of systematic risk to portfolio selection is illustrated.

In this paper, we aim to consider systematic risk and non-systematic risk to provide investors with strategies that satisfy their preference for assets. The main jobs of this paper are as follows. (1) In order to describe portfolio risk more carefully, we decompose risk into systematic and non-systematic risks. The two risks are measured by beta coefficient and random error square of Sharp Single Index Model, respectively. (2) In order to deal with the fuzzy objectives in the model, a goal programming method based on fuzzy dominance is proposed. Through this method, investors can determine a fuzzy return state satisfying themselves according to their risk preference. (3) A coefficient $\lambda$ is introduced to describe the degree of investors' attention to systematic risk. Through the sensitivity analysis of parameter $\lambda$, we reveal the impact of investors' attention to systematic risk on investment decision.

The rest of this paper is organized as follows. In Sect. 2, we introduce the possibility theory of fuzzy numbers, the relevant conclusions of triangular fuzzy numbers, Sharp Single Index Model and Shannon entropy. In Sect. 3, we put forward a novel fuzzy dominant goal programming on the basis of classical goal programming. In Sect. 4 and Sect. 5, a hybrid multi-objective model is constructed, and a numerical example is given to illustrate the feasibility of our model and the importance of the systematic risk. In Sect. 6, we draw the conclusion and present future research directions in goal programming and systematic risk.

\section{Preliminaries}

In this section, we will introduce some definitions about fuzzy theory and index model, which will be used in the following sections.

\subsection{Fuzzy set}

Fuzzy set is the extension of classical set. In classical set, there are only two kinds of relationships existing in an element and the set, namely belonging to or not belonging to. In other words, the membership function of a set is binary. Zadeh (1965) extended the concept of binary membership to the "membership degree" on the closed interval [0,1], where the two endpoints of 0 and 1 , respectively, represent completely belonging and not belonging, but the number between the two endpoints can represent the different membership degree of elements to the set. This kind of set including membership degree in the domain $X$ is called "fuzzy set."

A key difference between classical set and fuzzy set is a membership function. Classical sets have a unique membership function, while fuzzy sets may have infinite membership functions. For fuzzy sets, uniqueness is sacrificed, but flexibility is obtained.

Definition 2.1 (Zadeh 1965) The fuzzy set $A$ of domain $X$ is defined as

$A=\left\{\left(x, \mu_{A}(x)\right) \mid x \in X\right\}$.

where $\mu_{A}(x)$ is named membership function, which satisfies $A: X \rightarrow[0,1]$. Fuzzy set $A$ is also named fuzzy number. $[0,1]$ is called subordinate space. Additionally, it is 
easily found that fuzzy set is a mapping from domain $X$ to subordinate space actually.

Definition 2.2 (Zadeh 1965) Let $A$ be a fuzzy number with membership function $\mu_{A}(x)$. Then the $\gamma$-level set of fuzzy number $A$ is denoted by.

$[A]^{\gamma}=\left\{x \in X \mid \mu_{A}(x) \geq \gamma\right\}$.

Generally, we write it as $[A]^{\gamma}=[a(\gamma), \bar{a}(\gamma)]$ briefly.

Considering that investors have some subjective understanding of future return, some scholars study the portfolio on the basis of assuming that the return is fuzzy number. To some extent, fuzzifying returns is a proper method to quantify the subjective uncertainty.

Definition 2.3 (Zadeh 1965) If fuzzy number $A$ is equipped with membership function $\mu_{A}(x)$ as follows:

$\mu_{A}(x)= \begin{cases}1-\frac{a-x}{\alpha}, & a-\alpha \leq x<a, \\ 1, & x=a, \\ 1-\frac{x-a}{\beta}, & a<x \leq a+\beta, \\ 0, & \text { other. }\end{cases}$

Then the fuzzy number $A$ is called triangular fuzzy number, which is denoted as $A=(a, \alpha, \beta)$. According to Def. 2.2, the $\gamma$-level set of $A$ is $[a-\alpha(1-\gamma), a+\beta(1-\gamma)]$.

After giving the definition of triangular fuzzy numbers, we can define the arithmetic operation of triangular fuzzy numbers.

Definition 2.4 (Zadeh 1965) Let $A_{1}=\left(a_{1}, \alpha_{1}, \beta_{1}\right)$ and $A_{2}=\left(a_{2}, \alpha_{2}, \beta_{2}\right)$ be two triangular fuzzy numbers. Their corresponding $\gamma$-level sets are $\left[a_{1}(\gamma), \bar{a}_{1}(\gamma)\right]$ and $\left[a_{2}(\gamma), \bar{a}_{2}(\gamma)\right]$, respectively. Then their fuzzy addition and fuzzy scalar multiplication are, respectively, defined as follows:

Fuzzy addition:

$$
\begin{aligned}
A_{1}+A_{2} & =\left(a_{1}, \alpha_{1}, \beta_{1}\right)+\left(a_{2}, \alpha_{2}, \beta_{2}\right) \\
& =\left(a_{1}+a_{2}, \alpha_{1}+\alpha_{2}, \beta_{1}+\beta_{2}\right) .
\end{aligned}
$$

The form of $\gamma$-level set is denoted as

$$
\left[A_{1}+A_{2}\right]^{\gamma}=\left[a_{1}(\gamma)+a_{2}(\gamma), \bar{a}_{1}(\gamma)+\bar{a}_{2}(\gamma)\right] \forall \gamma \in[0,1] \text {. }
$$

Fuzzy scalar multiplication:

For every real number $\lambda$ and $A_{1}, \lambda A_{1}$ is denoted as

$$
\lambda A_{1}=\left\{\begin{array}{c}
\left(\lambda a_{1}, \lambda \alpha_{1}, \lambda \beta_{1}\right), \lambda \geq 0 \\
\left(\lambda a_{1}, \lambda \beta_{1}, \lambda \alpha_{1}\right), \lambda<0
\end{array}\right.
$$

\subsection{Possibility theory}

In fuzzy mathematics, membership degree is the foundation of fuzzy set theory, and membership function is the key to describe fuzziness. Referring to probability theory, we need theory to describe characteristics of fuzzy set corresponding to a membership function.

Definition 2.5 (Zadeh 1978) Let fuzzy number $A$ be equipped with $\gamma$-level set $[A]^{\gamma}=[a(\gamma), \bar{a}(\gamma)]$. Then some definitions about numerical characteristics of $A$ are given as follows:

Possibilistic mean of $A$ :

$$
E(A)=\int_{0}^{1} \gamma[a(\gamma)+\bar{a}(\gamma)] d \gamma \text {. }
$$

Possibilistic variance of $A$ :

$$
\operatorname{Var}(A)=\int_{0}^{1} \gamma\left\{[E(A)-a(\gamma)]^{2}+[E(A)-\bar{a}(\gamma)]^{2}\right\} d \gamma
$$

Possibilistic covariance of $A_{1}$ and $A_{2}$ :

$$
\begin{aligned}
\operatorname{Cov}\left(A_{1}, A_{2}\right)= & \int_{0}^{1} \gamma\left[\left(E\left(A_{1}\right)-a_{1}(\gamma)\right)\left(E\left(A_{2}\right)-a_{2}(\gamma)\right)\right. \\
& \left.+\left(E\left(A_{1}\right)-\bar{a}_{1}(\gamma)\right)\left(E\left(A_{2}\right)-\bar{a}_{2}(\gamma)\right)\right] d \gamma .
\end{aligned}
$$

Additionally, if $A_{i}$ are all fuzzy numbers, then some properties for arbitrary $\lambda_{i}$ belonging to real numbers are as follows,

$$
\begin{aligned}
E\left[\sum_{i=1}^{n} \lambda_{i} A_{i}\right]= & \sum_{i=1}^{n} \lambda_{i} E\left(A_{i}\right), \\
\operatorname{Var}\left[\sum_{i=1}^{n} \lambda_{i} A_{i}\right]= & \sum_{i=1}^{n} \lambda_{i}^{2} \operatorname{Var}\left(A_{i}\right) \\
& +2 \sum_{1 \leq i<j \leq n} \lambda_{i} \lambda_{j} \operatorname{Cov}\left(A_{i}, A_{j}\right) .
\end{aligned}
$$

According to Def. 2.5, we can calculate the numerical characteristics of triangular numbers $A=(a, \alpha, \beta)$ as follows.

$$
\begin{aligned}
& E(A)=a+\frac{\beta-\alpha}{6} . \\
& \operatorname{Var}(A)=\frac{(\alpha+\beta)^{2}}{24}+\frac{(\alpha-\beta)^{2}}{72} . \\
& \operatorname{Cov}\left(A_{1}, A_{2}\right)=\frac{\left(\alpha_{1}+\beta_{1}\right)\left(\alpha_{2}+\beta_{2}\right)}{36}+\frac{\alpha_{1} \alpha_{2}+\beta_{1} \beta_{2}}{36} .
\end{aligned}
$$




\subsection{Sharp Single Index Model}

In the financial market full of uncertain information, no matter how investors allocate assets, they will always face risks in the process of investment. Generally speaking, risks can be divided into two categories: systematic risk and non-systematic risk.

Systematic risk is also called non-diversification risk. As the name suggests, it cannot be avoided by diversification investment. It is usually caused by some common factors, which may bring huge losses to investors. The non-systematic risk is generally caused by the internal financial and operating conditions of the company. The black swan event in the investment field is usually caused by systematic risk. Therefore, this paper focuses on how investors make decisions considering both systematic and non-systematic risks.

Sharp Single Index Model (SSIM) proposed by Sharp shown the changing relationship between a single stock and the whole market, that is to say, it depicts the systematic risk of a single security. Besides, the variance of the random errors in the model corresponds to the nonsystematic risk of a single security. Before introducing Sharp Single Index Model, we illustrate some symbols in Table 1 first.

The Sharp Single Index Model is stated as follows:

$r_{j, t}=\alpha_{j}+\beta_{j} r_{m, t}+e_{j, t}$.

where $r_{j, t}$ is the return of security $j$ in time $t$ with $r_{j, t}=$ $p_{j, t}-p_{j, t-1}+d_{j, t} / p_{j, t-1} ; p_{j, t}$ is the price of security $j$ (for $j=1,2, \ldots, n)$ at time $t ; d_{j, t}$ is the dividend received during the period $[t-1, t] ; r_{m, t}$ is the return on the market index in period $t ; e_{j, t}$ is the random error of security $j$ in time $t . \alpha_{j}$ and $\beta_{j}$ are the coefficients to be estimated.

Table 1 Some symbol illustrations about SSIM

\begin{tabular}{ll}
\hline Symbol & Illustration \\
\hline$r_{j, t}$ & The return of security $j$ in time $t$ \\
$r_{m, t}$ & The return of market index in time $t$ \\
$p_{j, t}$ & The price of security $j$ in time $t$ \\
$d_{j, t}$ & The dividend of security $j$ time $t$ \\
$\alpha_{j}$ & The intercept parameter of security $j$ \\
$\beta_{j}$ & The slope parameter of security $j$ \\
$e_{j, t}$ & The random error of security $j$ in time $t$ \\
$\sigma_{e j}^{2}$ & The variance of the security $j$ random error \\
$\sigma_{m}^{2}$ & The variance of market index return \\
$\sigma_{p}^{2}$ & The variance of the portfolio \\
\hline
\end{tabular}

The coefficients $\alpha_{j}$ and $\beta_{j}$ are obtained by linear regression of market returns on the securities returns at the same period. The method used is named as ordinary least squares. The beta coefficient of stock $j$ is given by

$\beta_{j}=\frac{\sigma_{j} \sigma_{m}}{\sigma_{m}^{2}}$.

The beta of the portfolio is defined as a weighted average of the security betas $\beta_{p}=\sum_{j=1}^{n} x_{j} \beta_{j}$, which is used to measure the systematic risk. Then the risk of the portfolio is as follow:

$\sigma_{p}^{2}=\beta_{p}^{2} \sigma_{m}^{2}+\sum_{j=1}^{n} x_{j}^{2} \sigma_{e, j}^{2}$.

The last term tends toward 0 for a sufficiently large $n$. Therefore, the risk of a broadly diversified portfolio is only made up of the market risk. But in real investment, investors don't have enough money to buy enough securities. In order to measure the risk of portfolio, we should consider the last term. In ordinary least squares, the sum of squares of residuals divided by degrees of freedom is used to estimate $\sigma_{e, j}^{2}$, namely $\sigma_{e, j}^{2}=\frac{\sum_{t=1}^{n}\left(r_{j, t}-\widehat{r_{j t}}\right)^{2}}{n-2}$. According to Sharp Single Index Model, $\beta_{p}^{2} \sigma_{m}^{2}$ can be regarded as systematic risk and $\sum_{j=1}^{n} x_{j}^{2} \sigma_{e, j}^{2}$ can be regarded as non-systemic risk.

\subsection{Entropy}

In traditional MV model, it is easy to output extreme solution. Therefore, entropy is a measurement to guarantee the final investment decision is diversified enough. Now if investors prepare to invest $n$ securities, then we will get an investment proportion $x=\left(x_{1}, x_{2}, \ldots, x_{n}\right)^{T}$ finally. In this paper, the Shannon entropy is used to measure the degree of portfolio diversification. Its explicit expression is

$E=-\sum_{j=1}^{n} x_{j} \ln x_{j}$.

\section{Novel fuzzy dominant goal programming}

When investors make investment decisions, they often need to consider multiple conflicting objectives. If we consider all the objectives in the portfolio model, the traditional linear programming method cannot solve the model. According to multi-objectives problems, the classical method is transferring multi-objectives to a single objective. Recently, goal programming as a popular method to solve the problem of multi-objective portfolio has gradually come into the vision of scholars. 


\subsection{Classical goal programming}

Classical goal programming is developed on the basis of linear programming. The following sections introduce the concept related to the establishment of mathematical model by goal programming.

\subsubsection{Some characteristics of classical goal programming}

Compared to traditional linear programming, goal programming has the following characteristics.

\section{- Positive and negative deviation variables}

Let $d$ be a decision variable of objective functions. Then positive deviation variable $d^{+}=\max \left\{d-d_{0}, 0\right\}$ denotes the part of the objective function value exceeding the target value and the negative deviation variable $d^{-}=-\min \left\{d-d_{0}, 0\right\}$ denotes the part of the objective function value that does not reach the target value, where $d_{0}$ denotes the target value. Additionally, because the decision value cannot exceed the target value and fail to reach the target value, there is constraint $d^{+} \times d^{-}=0$.

- Absolute and objective constraints

Absolute constraints refer to equality constraints and inequality constraints that must be strictly satisfied. If all the constraints in linear programming cannot meet these constraints, the solution is called infeasible solution, so they are hard constraints. Objective constraint is unique to goal programming. When the target value is reached, positive or negative deviation can be allowed. Therefore, adding positive and negative deviation variables to these constraints is a soft constraint.

\section{- Objective function in goal programming}

The objective function of goal programming is constructed according to the positive and negative deviation variables of each objective constraint. When each target value is determined, it requires decision makers to reduce the deviation from the target value as much as possible. Generally speaking, the objective function of goal programming is $\min z=f\left(d^{+}, d^{-}\right)$. There are three basic forms as follows:

Case 1 If the requirement just meets the objective value, namely, the positive and negative deviation variables should be as few as possible. The objective function is $\min z=f\left(d^{+}+d^{-}\right)$.

Case 2 If the requirement does not exceed the objective value, namely, the positive deviation variables should be as few as possible. The objective function is $\min z=f\left(d^{+}\right)$.
Case 3 If the requirement exceeds the objective value, namely, the positive deviation variables should be as few as possible. The objective function is $\min z=f\left(d^{-}\right)$.

\subsubsection{Concrete calculation steps of classical goal programming}

The following shows the transformation from a specific multi-objective model to a goal planning model.

A multi-objective model corresponding to the above three cases can be stated as

$\left\{\begin{array}{l}\operatorname{opt} F_{1}(x)=a \\ \max F_{2}(x) \\ \min F_{3}(x) \\ \text { s.t. } H_{i}(x) \leq b, i=1,2, \ldots, n \\ x \geq 0 .\end{array}\right.$

$x=\left(x_{1}, x_{2}, \ldots, x_{n}\right)^{T}$ is a vector. All the objective functions can be expressed as the form of objective function in the aforesaid model. After the following steps, the above model can be transformed into a goal programming model.

Step 1 Calculate the optimal value of each objective function under constraints, respectively, which are written as $d_{1}, d_{2}, d_{3}$, especially $d_{1}=a$.

Step 2 Choose proper objective function by positive deviation variables and negative deviation variables, namely, $\min z=f_{1}\left(d_{1}^{+}+d_{1}^{-}\right)+f_{2}\left(d_{2}^{-}\right)+f_{3}\left(d_{3}^{+}\right)$.

Step 3 Rewrite model (15) as

$$
\left\{\begin{array}{l}
\min z=f_{1}\left(d_{1}^{+}+d_{1}^{-}\right)+f_{2}\left(d_{2}^{-}\right)+f_{3}\left(d_{3}^{+}\right) \\
\text {s.t. } H_{i}(x) \leq b, i=1,2, \ldots, n \\
F_{1}(x)+d_{1}^{-}-d_{1}^{+}=a=d_{1} \\
F_{2}(x)+d_{2}^{-}=d_{2} \\
F_{3}(x)-d_{3}^{-}=d_{3} \\
d_{1}^{+} \times d_{1}^{-}=0 \\
x \geq 0 .
\end{array}\right.
$$

\subsection{Fuzzy dominant goal programming}

It is obvious found that the key steps of transforming multiobjective model into goal programming model are to calculate the target value and construct the objective function. The general multi-objective model can be transformed into the corresponding goal programming model according to the above three steps. However, if the objective functions in the multi-objective model include fuzzy numbers, goal programming cannot solve this kind of models. This section proposes a method to find fuzzy deviation variables based on fuzzy dominance. 
First, we consider a fuzzy linear objective function $\max z=\sum_{i=1}^{n} x_{i} r_{i}$, where $x_{i}(i=1,2, \ldots, n)$ are decision variables and $r_{i}(i=1,2, \ldots, n)$ are fuzzy numbers. In order to concretize function, we can even suppose $r_{i}=\left(a_{i}, \alpha_{i}, \beta_{i}\right)(i=1,2, \ldots, n)$; namely, they are triangular fuzzy numbers. Then the objective function can be rewritten as.

$\max z=\sum_{i=1}^{n} x_{i} r_{i}=\left(\sum_{i=1}^{n} x_{i} a_{i}, \sum_{i=1}^{n} x_{i} \alpha_{i}, \sum_{i=1}^{n} x_{i} \beta_{i}\right)$

\subsubsection{A new definition of fuzzy dominance}

It is found that the objective function is a triangular fuzzy number with decision variables. That means the optimal objective value is also a triangular fuzzy number, denoting the optimal objective value as $z^{*}=\left(a^{*}, \alpha^{*}, \beta^{*}\right)$. Based on this, we need to define dominant fuzzy state.

Definition 3.1 Let $A_{1}=\left(a_{1}, \alpha_{1}, \beta_{1}\right)$ and $A_{2}=\left(a_{2}, \alpha_{2}, \beta_{2}\right)$ be two triangular fuzzy numbers. They also represent the same return objective. Then $A_{1} \succ A_{2}$ iff $a_{1}>a_{2}$. If they represent loss objective, then $A_{1} \succ A_{2}$ iff $a_{1}<a_{2}$. If $a_{1}=a_{2}$, the fuzzy numbers $A_{1}$ and $A_{2}$ are equivalent in theory.

Remark Although the fuzzy numbers $A_{1}$ and $A_{2}$ are equivalent in theory when $a_{1}=a_{2}$. In practical application, the two fuzzy numbers can be sorted in relative order according to the actual situation. For example, we apply this definition to portfolio decision. The optimistic investors prefer the fuzzy numbers whose $\beta$ is larger and $\alpha$ is smaller. But the pessimistic investors prefer the fuzzy numbers whose $\beta$ is smaller and $\alpha$ is larger.

Therefore, let $a^{*}=\max \sum_{i=1}^{n} x_{i} a_{i}$, which satisfies $z^{*} \succ z$. Then $\alpha^{*}$ and $\beta^{*}$ depend on people's subjective attitude. If optimistic, they hope the degree of membership is as low as possible to the left of the central value and as high as possible to the right of the central value. That means $\alpha^{*}=\min \sum_{i=1}^{n} x_{i} \alpha_{i}, \quad \beta^{*}=\max \sum_{i=1}^{n} x_{i} \beta_{i}, \quad$ namely, $z^{*}=\left(\max \sum_{i=1}^{n} x_{i} a_{i}, \min \sum_{i=1}^{n} x_{i} \alpha_{i}, \max \sum_{i=1}^{n} x_{i} \beta_{i}\right)$. If pessimistic, they hope the degree of membership is as low as possible to the right of the center value and as high as possible to the left of the center value.

\subsubsection{Specific description of fuzzy dominant goal programming}

In other words, compared to classical fuzzy goal programming, we should preferentially deal with fuzzy objective functions $\max z=\sum_{i=1}^{n} x_{i} r_{i}=\left(\sum_{i=1}^{n} x_{i} a_{i}\right.$, $\left.\sum_{i=1}^{n} x_{i} \alpha_{i}, \sum_{i=1}^{n} x_{i} \beta_{i}\right)$ before Step 1- Step 3 .

Step 0 Transform fuzzy objective function into a multiobjective problem. There are two cases shown as follows:
Case 1 If investors are optimistic, we should calculate three target values, namely the maximum of the central value, the minimum of the left width and the maximum of the right width. That is

$\left\{\begin{array}{l}\max \sum_{i=1}^{n} x_{i} a_{i}, \\ \min \sum_{i=1}^{n} x_{i} \alpha_{i}, \\ \max \sum_{i=1}^{n} x_{i} \beta_{i} .\end{array}\right.$

Then we set the optimal values as $\left(a^{*}, \alpha^{*}, \bar{\beta}^{*}\right)$ and take the three values as target to construct goal programming model as follows.

$$
\left\{\begin{array}{l}
\min f_{1}\left(d_{1}^{-}\right)+f_{2}\left(d_{2}^{+}\right)+f_{3}\left(d_{3}^{-}\right) \\
\text {s.t. } \sum_{i=1}^{n} x_{i} a_{i}+d_{1}^{-}=a^{*} \\
\sum_{i=1}^{n} x_{i} \alpha_{i}-d_{2}^{+}=\alpha^{*} \\
\sum_{i=1}^{n} x_{i} \beta_{i}+d_{3}^{-}=\bar{\beta}^{*} .
\end{array}\right.
$$

Case 2 If investors are pessimistic, we should calculate three target values, namely the maximum of the central value, the maximum of the left width and the minimum of the right width.

$$
\left\{\begin{array}{l}
\max \sum_{i=1}^{n} x_{i} a_{i} \\
\max \sum_{i=1}^{n} x_{i} \alpha_{i} \\
\min \sum_{i=1}^{n} x_{i} \beta_{i} .
\end{array}\right.
$$

Then we set the optimal values as $\left(a^{*}, \bar{\alpha}^{*}, \beta^{*}\right)$ and take the three values as target to construct goal programming model as follows.

$$
\left\{\begin{array}{l}
\min f_{1}\left(d_{1}^{-}\right)+f_{2}\left(d_{2}^{+}\right)+f_{3}\left(d_{3}^{-}\right) \\
\text {s.t. } \sum_{i=1}^{n} x_{i} a_{i}+d_{1}^{-}=a^{*} \\
\sum_{i=1}^{n} x_{i} \alpha_{i}-d_{2}^{+}=\bar{\alpha}^{*} \\
\sum_{i=1}^{n} x_{i} \beta_{i}+d_{3}^{-}=\beta^{*}
\end{array}\right.
$$

After Step 0, we can get two statuses of dominant fuzzy return responding to optimistic and pessimistic investors, 
respectively. These two statuses are shown geometrically in Fig. 1.

From Fig. 1, it is obvious that the investors have the same target central value no matter they are optimistic or pessimistic, which means they have the same average return anticipation. But the optimistic investors have higher membership degree than the pessimistic ones when the portfolio return exceeds the central value. On the contrary, the optimistic investors have lower membership degree than the pessimistic ones when the portfolio return does not reach the central value. This reflects the investors' attitude to future portfolio return to some extent.

\section{Portfolio model with systematic and non- systematic risks}

Before making investment decisions, investors often need to consider the historical return, risk status and current investment environment of securities. Due to the subjectivity of investors themselves, there are some deviations in their cognition of future returns and risks. Therefore, this paper studies the problem of portfolio selection in fuzzy environment. Beta coefficient is used to measure the systematic risk hidden in investment environment.

\subsection{Model description}

Before constructing the portfolio model, we first give a brief description of the model's notation (Table 2).

Remark $T$ represents a period, and $t$ represents a time point in period $T$.

In this paper, we assume that investors adopt positive investment strategies. That means they will change the investment proportion and adjust the investment strategy in real time according to the market situation. In order to simplify the multi-period model, it is assumed that investors invest in a frictionless financial market. In other words, the investors are not required to pay transaction fees and

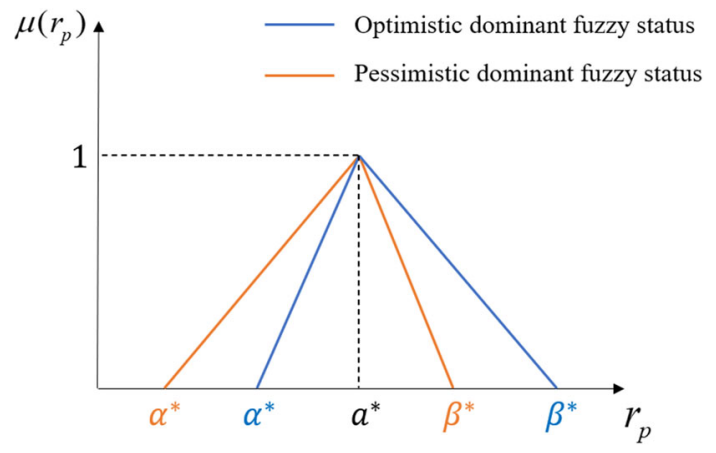

Fig. 1 Fuzzy dominant status for optimistic and pessimistic investors taxes when they sell securities, buying securities and earning from securities.

In our proposed model, three objectives are considered, which are return, risk and entropy. According to return, we adopt the method of fuzzification to deal with it. Suppose that investors plan to invest $k$ securities, we set the fuzzy return of each security $\tilde{r}_{i T}=\left(a_{i T}, \alpha_{i T}, \beta_{i T}\right)$ $(i=1,2, \ldots, k ; t \in T)$. Then we can construct a fuzzy portfolio, whose fuzzy return is $\tilde{r}_{p T}=\left(a_{p T}, \alpha_{p T}, \beta_{p T}\right)=$ $\left(\sum_{i=1}^{k} x_{i T} a_{i T}, \sum_{i=1}^{k} x_{i T} \alpha_{i T}, \sum_{i=1}^{k} x_{i T} \beta_{i T}\right)$ in period $T$. What we do is to find an optimal fuzzy portfolio status. According to risk, both systematic risk and non-systematic risk are considered into model. The beta coefficient is used to measure systematic risk, and the sum of squares of residuals is used to measure non-systematic risk by the regression of securities and market index. Finally, the entropy as an objective is to guarantee the final result diversification.

\subsection{Steps of model construction}

In this paper, we consider three objectives: fuzzy return status, the total risk and the diversification degree. The model construction steps can be described as follows.

Step 1 Basic model construction

$$
\left\{\begin{array}{l}
\operatorname{opt} \tilde{r}_{p T}=\left(a_{p T}, \alpha_{p T}, \beta_{p T}\right)=\left(\sum_{i=1}^{k} x_{i T} a_{i T}, \sum_{i=1}^{k} x_{i T} \alpha_{i T}, \sum_{i=1}^{k} x_{i T} \beta_{i T}\right) \\
\min \sigma_{p T}^{2}=\lambda \beta_{p T}^{2} \sigma_{m T}^{2}+\mu \sum_{i=1}^{k} x_{i T} \sigma_{n i T}^{2} \\
\max E=-\sum_{i=1}^{k} x_{i} \ln x_{i} \\
\text { s.t. } \sum_{i=1}^{k} x_{i}=1, \lambda+\mu=1 \\
x_{i T}, \lambda, \mu \geq 0, i=1, \ldots, k .
\end{array}\right.
$$

The first objective requires finding a dominant fuzzy portfolio status, which is not a traditional objective function. According to the second objective, it is essentially a linear weighting function with systematic risk and nonsystematic risk. The parameters in this function are calculated as follows: $\beta_{p T}=\sum_{i=1}^{k} x_{i T} \beta_{i T}$. $\beta_{i T}$ and $\sigma_{n i T}^{2}$ both can be obtained by Sharp Single Index Model in the $i$ security and the market index, which represent beta coefficient and sum of squares of residuals separately. The last objective requires our portfolio as diverse as possible.

Step 2 Sub-models for objective. 
Table 2 Illustration of symbols

\begin{tabular}{ll}
\hline Symbols & Illustration \\
\hline$r_{i t}$ & The dataset of the return of security $i$ in time $t$ \\
$r_{m t}$ & The dataset of the return of market index in time $t$ \\
$\beta_{i T}$ & The beta coefficient of the security $i$ in period $T$ \\
$\beta_{p T}$ & The beta coefficient of the portfolio in period $T$ \\
$\sigma_{n i T}^{2}$ & The non-systematic risk of the security $i$ in period $T$ \\
$\sigma_{s i T}^{2}$ & The systematic risk of the security $i$ in period $T$ \\
$\sigma_{p T}^{2}$ & The total risk of the portfolio in period $T$ \\
$\tilde{r}_{i T}=\left(a_{i T}, \alpha_{i T}, \beta_{i T}\right)$ & The fuzzy return of security $i$ in period $T$ \\
$\tilde{r}_{p T}=\left(a_{p T}, \alpha_{p T}, \beta_{p T}\right)$ & The fuzzy return of the portfolio in period $T$ \\
$x_{T}=\left(x_{1 T}, x_{2 T}, \ldots, x_{k T}\right)^{\prime}$ & The vector of Investment proportion in period $T$ \\
\hline
\end{tabular}

Our proposed model is not a traditional linear program model. We solve it by the method in Sect. 3. Firstly, we solve the following sub-models:

$$
\left\{\begin{array}{l}
\max \sum_{i=1}^{k} x_{i T} a_{i T} \\
\text { s.t. } \sum_{i=1}^{k} x_{i T}=1 \\
x_{i T} \geq 0, i=1, \ldots, k .
\end{array}\right.
$$

where $a_{i T}$ represent the central value of the $i$ th security fuzzy return.

$$
\left\{\begin{array}{l}
\max \sum_{i=1}^{k} x_{i T} \alpha_{i T} \\
\text { s.t. } \sum_{i=1}^{k} x_{i T}=1 \\
x_{i T} \geq 0, i=1, \ldots, k .
\end{array}\right.
$$

where $\alpha_{i T}$ represent the left width of the $i$ th security fuzzy return.

$$
\begin{aligned}
& \left\{\begin{array}{l}
\min \sum_{i=1}^{k} x_{i T} a_{i T} \\
\text { s.t. } \sum_{i=1}^{k} x_{i T}=1 \\
x_{i T} \geq 0, i=1, \ldots, k .
\end{array}\right. \\
& \left\{\begin{array}{l}
\max \sum_{i=1}^{k} x_{i t} \beta_{i t} \\
\text { s.t. } \sum_{i=1}^{k} x_{i T}=1 \\
x_{i T} \geq 0, i=1, \ldots, k .
\end{array}\right.
\end{aligned}
$$

$$
\begin{aligned}
& \left\{\begin{array}{l}
\min \sum_{i=1}^{k} x_{i T} \beta_{i T} \\
\text { s.t. } \sum_{i=1}^{k} x_{i T}=1 \\
x_{i T} \geq 0, i=1, \ldots, k .
\end{array}\right. \\
& \left\{\begin{array}{l}
\min \sigma_{p T}^{2}=\lambda \beta_{p T}^{2} \sigma_{m T}^{2}+\mu \sum_{i=1}^{k} x_{k T} \sigma_{n i T}^{2} \\
\text { s.t. } \sum_{i=1}^{k} x_{i T}=1, \lambda+\mu=1 \\
x_{i T}, \lambda, \mu \geq 0, i=1, \ldots, k . \\
\max E=-\sum_{i=1}^{k} x_{i T} \ln x_{i T} \\
\text { s.t. } \sum_{i=1}^{k} x_{i T}=1 \\
x_{i T} \geq 0, i=1, \ldots, k .
\end{array}\right.
\end{aligned}
$$

Step 3 One single objective model with deviation variable.

We mark the target values of the above models as follows: $a^{*}, \bar{\alpha}^{*}, \alpha^{*}, \bar{\beta}^{*}, \beta^{*}, \sigma^{*}, E^{*}$. Then we can convert the original model into two single objective models for optimistic and pessimistic investors separately. 


$$
\begin{aligned}
& \left\{\begin{array}{l}
\min d=d_{1}+d_{2}+d_{3}+d_{4}+d_{5} \\
\text { s.t. } \sum_{i=1}^{k} x_{i T} a_{i T}+d_{1}=a^{*} \sum_{i=1}^{k} x_{i T} \alpha_{i T}-d_{2}=\alpha^{*}, \\
\sum_{i=1}^{k} x_{i T} \beta_{i T}+d_{3}=\bar{\beta}^{*}-\sum_{i=1}^{k} x_{i T} \ln x_{i T}+d_{5}=E^{*}, \\
\lambda \beta_{p T}^{2} \sigma_{m T}^{2}+\mu \sum_{i=1}^{k} x_{k T} \sigma_{n i T}^{2}-d_{4}=\sigma^{*}, \\
\sum_{i=1}^{k} x_{i T}=1 \lambda+\mu=1, \\
x_{i T}, \lambda, \mu \geq 0, i=1, \ldots, k . \\
\min d=d_{1}+d_{2}+d_{3}+d_{4}+d_{5} \\
\text { s.t. } \sum_{i=1}^{k} x_{i T} a_{i T}+d_{1}=a^{*}, \sum_{i=1}^{k} x_{i T} \alpha_{i T}+d_{2}=\bar{\alpha}^{*}, \\
\sum_{i=1}^{k} x_{i T} \beta_{i T}-d_{3}=\beta^{*},-\sum_{i=1}^{k} x_{i T} \ln x_{i T}+d_{5}=E^{*}, \\
\lambda \beta_{p T}^{2} \sigma_{m T}^{2}+\mu \sum_{i=1}^{k} x_{k T} \sigma_{n i T}^{2}-d_{4}=\sigma^{*}, \\
\sum_{i=1}^{k} x_{i T}=1, \lambda+\mu=1, \\
x_{i T}, \lambda, \mu \geq 0, i=1, \ldots, k .
\end{array}\right.
\end{aligned}
$$

\section{Numerical example}

\subsection{Data processing}

Since the COVID-19 outbreak, securities in different industries of the financial market have suffered different impacts. In this paper, we analyze the securities from hygiene, pharmaceutical manufacturing and fishery. We choose three securities in each of the three industries to invest and study how we should invest in them under special circumstances. We denote the securities as $S_{i}(i=1, \ldots, 9)$ before the establishment of the model. We collected the corresponding data in NETEASE, which are shown in Table 3.

For Table 3, we make the following explanations. Considering that investors will evaluate the yield of securities subjectively, we refer to the method of Vercher and Bermudez (2013) to fuzzify the return data. We use triangular fuzzy numbers $(a, \alpha, \beta)$ to express the rate of return. We adopt the quantile method. In the dataset, we have taken the daily return data of various securities from February to July 2020. We divided the dataset into three phases. They represent before, during and after the COVID-19 outbreak, respectively, where $a$ is the median return of the corresponding security. $\alpha$ is the difference between the $5 \%$ quantile and the median. $\beta$ is the difference between the $95 \%$ quantile and the median. Then we regress the securities returns and CSI 300 index based on Sharp Single Index Model. Beta is the slope parameter of SSIM. And the non-systematic risk is measured by the variance of random errors.

\subsection{Solution on constructed models}

Step 1 Original model construction.

According to model (27), we obtain the corresponding models in each period. All the obtained modes are triobjective models with a fuzzy objective function, which should be solved by our proposed fuzzy dominant goal programming method.

$$
\left\{\begin{array}{l}
\text { opt } \tilde{r}_{p 1}=\left(0.29 x_{11}+0.45 x_{21}+0.45 x_{31}+0.64 x_{41}-0.08 x_{51}+0.48 x_{61}+0.77 x_{71}-0.32 x_{81}+0.97 x_{91}\right. \\
1.56 x_{11}+1.62 x_{21}+1.98 x_{31}+2.47 x_{41}+1.60 x_{51}+1.52 x_{61}+2.07 x_{71}+1.32 x_{81}+2.34 x_{91}, \\
\left.1.48 x_{11}+1.28 x_{21}+1.37 x_{31}+1.60 x_{41}+1.26 x_{51}+1.99 x_{61}+2.12 x_{71}+1.18 x_{81}+1.69 x_{91}\right) \\
\min \sigma_{p 1}^{2}=\lambda\left(2.8 x_{11}+1.1 x_{21}+2.2 x_{31}+1.5 x_{41}+2.3 x_{51}+1.9 x_{61}+1.7 x_{71}+2.21 x_{81}+0.8 x_{91}\right)^{2}+(1-\lambda) \\
\quad\left(2.49 x_{11}+3.48 x_{21}+3.13 x_{31}+3.82 x_{41}+3.01 x_{51}+3.29 x_{61}+3 x_{71}+2.21 x_{81}+4.23 x_{91}\right) \\
\max E=-\sum_{i=1}^{9} x_{i 1} \ln x_{i 1} \\
\text { s.t. } \sum_{i=1}^{9} x_{i 1}=1 \\
x_{i 1} \geq 0, i=1, \ldots, 9 .
\end{array}\right.
$$




$$
\begin{aligned}
& \text { opt } \tilde{r}_{p 2}=\left(-0.02 x_{12}+0.76 x_{21}+0.36 x_{32}-0.16 x_{42}+0.3 x_{52}-0.3 x_{62}+0.1 x_{72}-0.32 x_{82}+0.01 x_{92}\right. \text {, } \\
& 2.44 x_{12}+2.61 x_{21}+1.24 x_{32}+2.22 x_{42}+1.08 x_{52}+0.93 x_{62}+2.12 x_{72}+1.64 x_{82}+1.69 x_{92}, \\
& \left.1.28 x_{12}+2.19 x_{21}+1.1 x_{32}+1.6 x_{42}+1.96 x_{52}+1.19 x_{62}+1.95 x_{72}+1.01 x_{82}+1.71 x_{92}\right) \\
& \min \sigma_{p 2}^{2}=\lambda\left(1.2 x_{12}+0.9 x_{22}+1.5 x_{32}+0.3 x_{42}+0.7 x_{52}+2.1 x_{62}+4.9 x_{72}+3.4 x_{82}+3 x_{92}\right)^{2}+(1-\lambda) \\
& \left(2.48 x_{12}+3.28 x_{22}+2.44 x_{32}+4.06 x_{42}+2.68 x_{52}+1.81 x_{62}+3.01 x_{72}+2.46 x_{82}+3.16 x_{92}\right) \\
& \max E=-\sum_{i=1}^{9} x_{i 2} \ln x_{i 2} \\
& \begin{array}{l}
\text { s.t. } \sum_{i=1}^{9} x_{i 2}=1 \\
x_{i 2} \geq 0, i=1, \ldots, 9 .
\end{array} \\
& \left\{\begin{array}{l}
\text { opt } \tilde{r}_{p 3}=\left(0.29 x_{13}+0.16 x_{23}+0.23 x_{33}-0.38 x_{43}+0.34 x_{53}-0.07 x_{63}-0.27 x_{73}-0.41 x_{83}-0.09 x_{93},\right. \\
1.87 x_{13}+1.45 x_{23}+1.78 x_{33}+2.88 x_{43}+2.06 x_{53}+1.74 x_{63}+2.1 x_{73}+2.37 x_{83}+1.39 x_{93}, \\
\left.2 x_{13}+1.94 x_{23}+1.5 x_{33}+2.4 x_{43}+1.99 x_{53}+1.73 x_{63}+2.13 x_{73}+1.82 x_{83}+1.6 x_{93}\right) \\
\min \sigma_{p 3}^{2}=\lambda\left(1.9 x_{13}+2.3 x_{23}+5.1 x_{33}+1.1 x_{43}+3.8 x_{53}+1.5 x_{63}+3.9 x_{73}+3.6 x_{83}+4 x_{93}\right)^{2}+(1-\lambda) \\
\quad\left(5.04 x_{13}+4.08 x_{23}+2.93 x_{33}+4.32 x_{43}+3.13 x_{53}+3.06 x_{63}+4.19 x_{73}+3.98 x_{83}+3.24 x_{93}\right) \\
\max E=-\sum_{i=1}^{9} x_{i 3} \ln x_{i 3} \\
\text { s.t. } \sum_{i=1}^{9} x_{i 3}=1 \\
x_{i 3} \geq 0, i=1, \ldots, 9 .
\end{array}\right.
\end{aligned}
$$

In models (32)-(34), $\lambda$ can take values from 0 to 1 which represents the investors' attention to systematic risk. In this paper, we take $\lambda$ to be $0,0.25,0.5,0.75$ and 1 successively.

Step 2 Sub-models for objective.

According to sub-models (23)-(29), we calculate the optimal value of all objective functions in models (32)-(34) during their corresponding constraint domain. As the $\lambda$ value varies, we get the corresponding target value in each period.

In Table 4, we can find an interesting phenomenon. With the $\lambda$ value increasing, the optimal value of $\sigma^{*}$ presents a trend of first increasing and then decreasing, which means that if we pay more attention or less to systematic risk, the total risk would be underestimate without considering other objective functions. In other words, the total risk of portfolio can be effectively evaluated by properly considering systematic risk.

Step 3 One single model with deviation variable.

For this numerical example, because $\lambda$ can value different numbers and there are three period data, we should solve fifteen single objective models finally. Here we take $T=1$ and $\lambda=0.5$ as an example. We write the corresponding models for optimistic and pessimistic investors, respectively. 
Table 3 The fuzzy return, beta coefficient and non-systematic risk of each security

\begin{tabular}{|c|c|c|c|c|c|}
\hline Industry & Securities & Period & Fuzzy return & Beta & Non-systematic risk \\
\hline \multirow[t]{9}{*}{ Hygiene } & \multirow[t]{3}{*}{$S_{1}$} & $T=1$ & $(0.29,1.56,1.48)$ & 2.8 & 2.49 \\
\hline & & $T=2$ & $(-0.02,2.44,1.28)$ & 1.2 & 2.48 \\
\hline & & $T=3$ & $(0.29,1.87,2.00)$ & 1.9 & 5.04 \\
\hline & \multirow[t]{3}{*}{$S_{2}$} & $T=1$ & $(0.45,1.62,2.40)$ & 1.1 & 3.48 \\
\hline & & $T=2$ & $(0.76,2.61,2.19)$ & 0.9 & 3.28 \\
\hline & & $T=3$ & $(0.16,1.45,1.94)$ & 2.3 & 4.08 \\
\hline & \multirow[t]{3}{*}{$S_{3}$} & $T=1$ & $(0.45,1.98,1.37)$ & 2.2 & 3.13 \\
\hline & & $T=2$ & $(0.36,1.24,1.10)$ & 1.5 & 2.44 \\
\hline & & $T=3$ & $(0.23,1.78,1.50)$ & 5.1 & 2.93 \\
\hline \multirow[t]{9}{*}{ Pharmaceutical } & \multirow[t]{3}{*}{$S_{4}$} & $T=1$ & $(0.64,2.47,1.60)$ & 1.5 & 3.82 \\
\hline & & $T=2$ & $(-0.16,2.22,1.60)$ & 0.3 & 4.06 \\
\hline & & $T=3$ & $(-0.38,2.88,2.40)$ & 1.1 & 4.32 \\
\hline & \multirow[t]{3}{*}{$S_{5}$} & $T=1$ & $(-0.08,1.60,1.26)$ & 2.3 & 3.01 \\
\hline & & $T=2$ & $(0.30,1.08,1.96)$ & 0.7 & 2.68 \\
\hline & & $T=3$ & $(0.34,2.06,1.99)$ & 3.8 & 3.13 \\
\hline & \multirow[t]{3}{*}{$S_{6}$} & $T=1$ & $(0.48,1.52,1.99)$ & 1.9 & 3.29 \\
\hline & & $T=2$ & $(-0.30,0.93,1.19)$ & 2.1 & 1.81 \\
\hline & & $T=3$ & $(-0.07,1.74,1.73)$ & 1.5 & 3.06 \\
\hline \multirow[t]{9}{*}{ Fishery } & \multirow[t]{3}{*}{$S_{7}$} & $T=1$ & $(0.77,2.07,2.12)$ & 1.7 & 3.00 \\
\hline & & $T=2$ & $(0.10,2.12,1.95)$ & 4.9 & 3.01 \\
\hline & & $T=3$ & $(-0.27,2.10,2.13)$ & 3.9 & 4.19 \\
\hline & \multirow[t]{3}{*}{$S_{8}$} & $T=1$ & $(0.31,1.32,1.18)$ & 4.0 & 2.21 \\
\hline & & $T=2$ & $(-0.32,1.64,1.01)$ & 3.4 & 2.46 \\
\hline & & $T=3$ & $(-0.41,2.37,1.82)$ & 3.6 & 3.98 \\
\hline & \multirow[t]{3}{*}{$S_{9}$} & $T=1$ & $(0.97,2.34,1.69)$ & 0.8 & 4.23 \\
\hline & & $T=2$ & $(0.01,1.69,1.71)$ & 3.0 & 3.16 \\
\hline & & $T=3$ & $(-0.09,1.39,1.60)$ & 4.0 & 3.24 \\
\hline
\end{tabular}

Table 4 Target values in models (32)-(34)

\begin{tabular}{lllllllll}
\hline$\lambda$ & $T$ & $a^{*}(23)$ & $\bar{\alpha}^{*}(24)$ & $\alpha^{*}(25)$ & $\bar{\beta}^{*}(26)$ & $\beta^{*}(27)$ & $\sigma^{*}(28)$ & $E^{*}(29)$ \\
\hline 0.00 & $T=1$ & 0.97 & 2.47 & 1.32 & 2.40 & 1.18 & 2.21 & 2.20 \\
& $T=2$ & 0.34 & 2.61 & 0.93 & 2.19 & 1.01 & 1.81 & 2.20 \\
0.25 & $T=3$ & 0.76 & 2.88 & 1.39 & 2.40 & 1.60 & 2.93 & 2.20 \\
& $T=1$ & 0.97 & 2.47 & 1.32 & 2.40 & 1.18 & 2.60 & 2.20 \\
& $T=2$ & 0.34 & 2.61 & 0.93 & 2.19 & 1.01 & 2.06 & 2.20 \\
0.50 & $T=3$ & 0.76 & 2.88 & 1.39 & 2.40 & 1.60 & 4.53 & 2.20 \\
& $T=1$ & 0.97 & 2.47 & 1.32 & 2.40 & 1.18 & 2.20 & 2.20 \\
& $T=2$ & 0.34 & 2.61 & 0.93 & 2.19 & 1.01 & 1.53 & 2.20 \\
& $T=3$ & 0.76 & 2.88 & 1.39 & 2.40 & 1.60 & 4.73 & 2.20 \\
& $T=1$ & 0.97 & 2.47 & 1.32 & 2.40 & 1.18 & 1.80 & 2.20 \\
& $T=2$ & 0.34 & 2.61 & 0.93 & 2.19 & 1.01 & 0.96 & 2.20 \\
& $T=3$ & 0.76 & 2.88 & 1.39 & 2.40 & 1.60 & 4.94 & 2.20 \\
& $T=1$ & 0.97 & 2.47 & 1.32 & 2.40 & 1.18 & 1.40 & 2.20 \\
& $T=2$ & 0.34 & 2.61 & 0.93 & 2.19 & 1.01 & 0.07 & 2.20 \\
& $T=3$ & 0.76 & 2.88 & 1.39 & 2.40 & 1.60 & 5.15 & 2.20 \\
\hline
\end{tabular}


Table 5 Portfolio solution for optimistic investors in models (32)-(34)

Table 6 Portfolio performance for optimistic investors $n$ models (32)-(34)

Fig. 2 The portfolio performance for optimistic investors when $T=1$

\begin{tabular}{lllllllllll}
\hline$\lambda$ & $\mathrm{T}$ & $S_{1}$ & $S_{2}$ & $S_{3}$ & $S_{4}$ & $S_{5}$ & $S_{6}$ & $S_{7}$ & $S_{8}$ & $S_{9}$ \\
\hline 0.00 & $\mathrm{~T}=1$ & 0.17 & 0.18 & 0.06 & 0.04 & 0.05 & 0.16 & 0.19 & 0.12 & 0.03 \\
& $\mathrm{~T}=2$ & 0.59 & 0.41 & 0.00 & 0.00 & 0.00 & 0.00 & 0.00 & 0.00 & 0.00 \\
& $\mathrm{~T}=3$ & 0.04 & 0.12 & 0.19 & 0.02 & 0.22 & 0.16 & 0.05 & 0.02 & 0.17 \\
0.25 & $\mathrm{~T}=1$ & 0.02 & 0.28 & 0.02 & 0.03 & 0.01 & 0.08 & 0.45 & 0.01 & 0.10 \\
& $\mathrm{~T}=2$ & 0.58 & 0.42 & 0.00 & 0.00 & 0.00 & 0.00 & 0.00 & 0.00 & 0.00 \\
& $\mathrm{~T}=3$ & 0.06 & 0.04 & 0.00 & 0.32 & 0.01 & 0.52 & 0.06 & 0.00 & 0.00 \\
0.50 & $\mathrm{~T}=1$ & 0.01 & 0.23 & 0.01 & 0.02 & 0.01 & 0.03 & 0.54 & 0.01 & 0.14 \\
& $\mathrm{~T}=2$ & 0.52 & 0.48 & 0.00 & 0.00 & 0.00 & 0.00 & 0.00 & 0.00 & 0.00 \\
& $\mathrm{~T}=3$ & 0.02 & 0.01 & 0.00 & 0.65 & 0.00 & 0.31 & 0.02 & 0.00 & 0.00 \\
& $\mathrm{~T}=1$ & 0.01 & 0.20 & 0.01 & 0.01 & 0.01 & 0.01 & 0.56 & 0.00 & 0.19 \\
& $\mathrm{~T}=2$ & 0.50 & 0.50 & 0.00 & 0.00 & 0.00 & 0.00 & 0.00 & 0.00 & 0.00 \\
& $\mathrm{~T}=3$ & 0.01 & 0.00 & 0.00 & 0.86 & 0.00 & 0.13 & 0.01 & 0.00 & 0.00 \\
& $\mathrm{~T}=1$ & 0.01 & 0.25 & 0.01 & 0.02 & 0.01 & 0.02 & 0.47 & 0.00 & 0.22 \\
& $\mathrm{~T}=2$ & 0.45 & 0.55 & 0.00 & 0.00 & 0.00 & 0.00 & 0.00 & 0.00 & 0.00 \\
& $\mathrm{~T}=3$ & 0.00 & 0.00 & 0.00 & 0.95 & 0.00 & 0.05 & 0.00 & 0.00 & 0.00 \\
\hline
\end{tabular}

\begin{tabular}{lllllll}
\hline$\lambda$ & $T$ & Possibilistic mean & Possibilistic variance & Total risk & Entropy & Industry Entropy \\
\hline 0.00 & $T=1$ & 0.47 & 0.50 & 3.03 & 2.03 & 1.08 \\
& $T=2$ & 0.16 & 0.73 & 2.81 & 0.68 & 0.00 \\
& $T=3$ & 0.10 & 0.52 & 3.35 & 1.93 & 1.08 \\
0.25 & $T=1$ & 0.64 & 0.61 & 3.27 & 1.50 & 0.94 \\
& $T=2$ & 0.17 & 0.76 & 2.83 & 0.68 & 0.00 \\
& $T=3$ & 0.16 & 0.71 & 5.15 & 1.22 & 0.54 \\
0.50 & $T=1$ & 0.67 & 0.61 & 2.91 & 1.31 & 0.77 \\
& $T=2$ & 0.22 & 0.76 & 2.37 & 0.69 & 0.00 \\
& $T=3$ & 0.31 & 0.92 & 5.49 & 0.85 & 0.22 \\
0.75 & $T=1$ & 0.69 & 0.61 & 2.45 & 1.19 & 0.76 \\
& $T=2$ & 0.24 & 0.76 & 1.37 & 0.69 & 0.00 \\
& $T=3$ & 0.40 & 1.07 & 5.49 & 0.49 & 0.10 \\
& $T=1$ & 0.69 & 0.64 & 2.41 & 1.33 & 0.65 \\
& $T=2$ & 0.24 & 0.78 & 0.84 & 0.69 & 0.00 \\
& $T=3$ & 0.40 & 1.12 & 5.34 & 0.20 & 0.00 \\
\hline
\end{tabular}

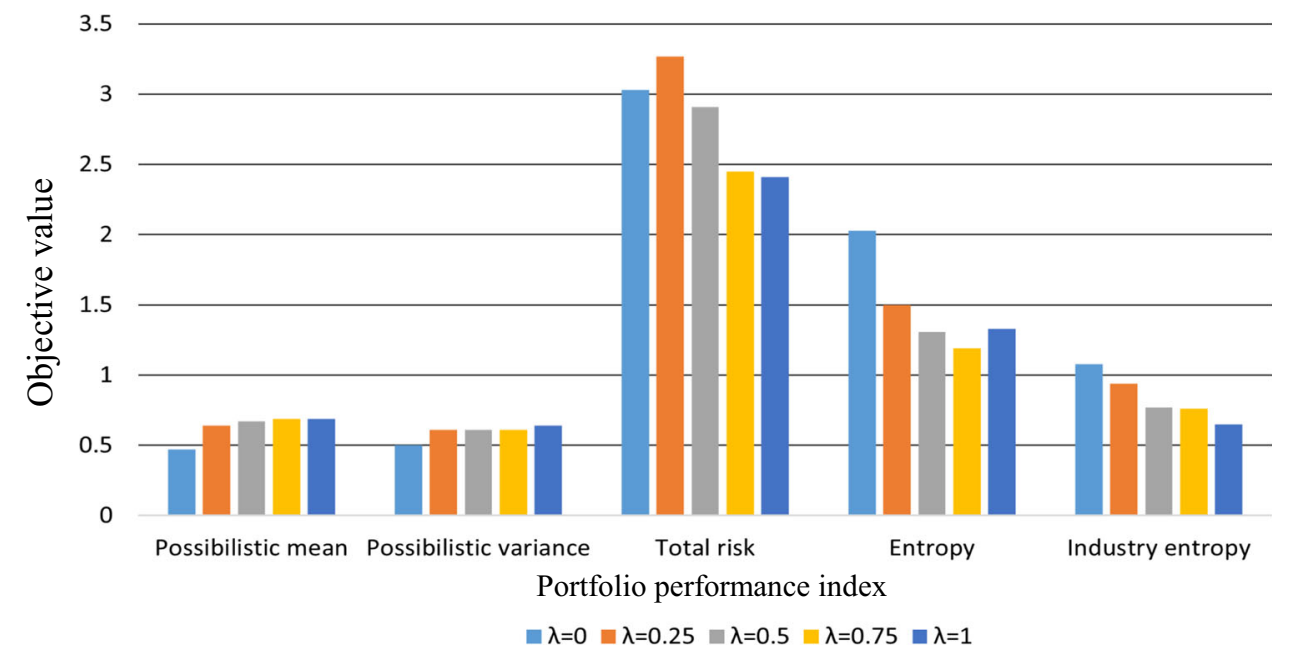




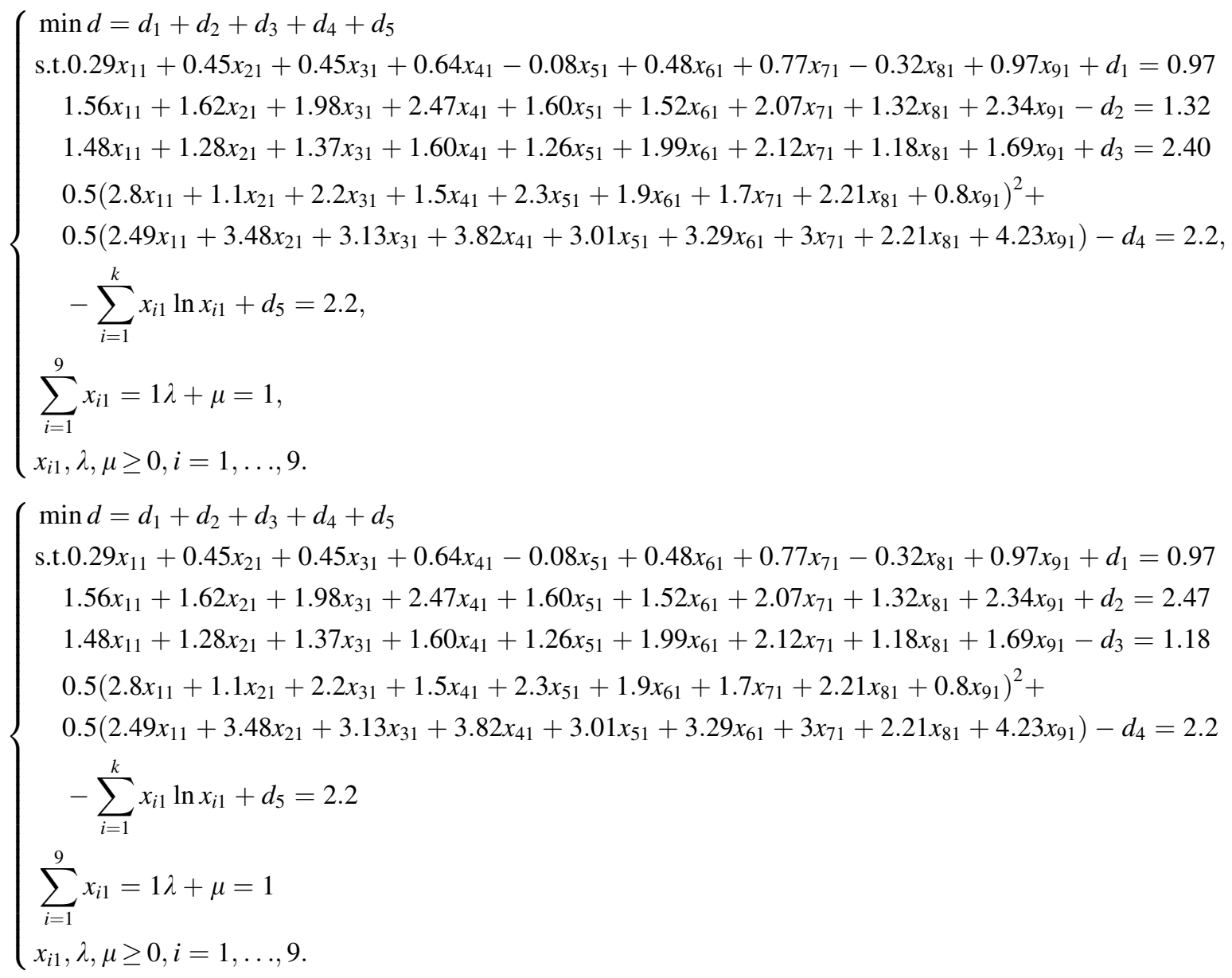

Fig. 3 The portfolio performance for optimistic investors when $T=2$

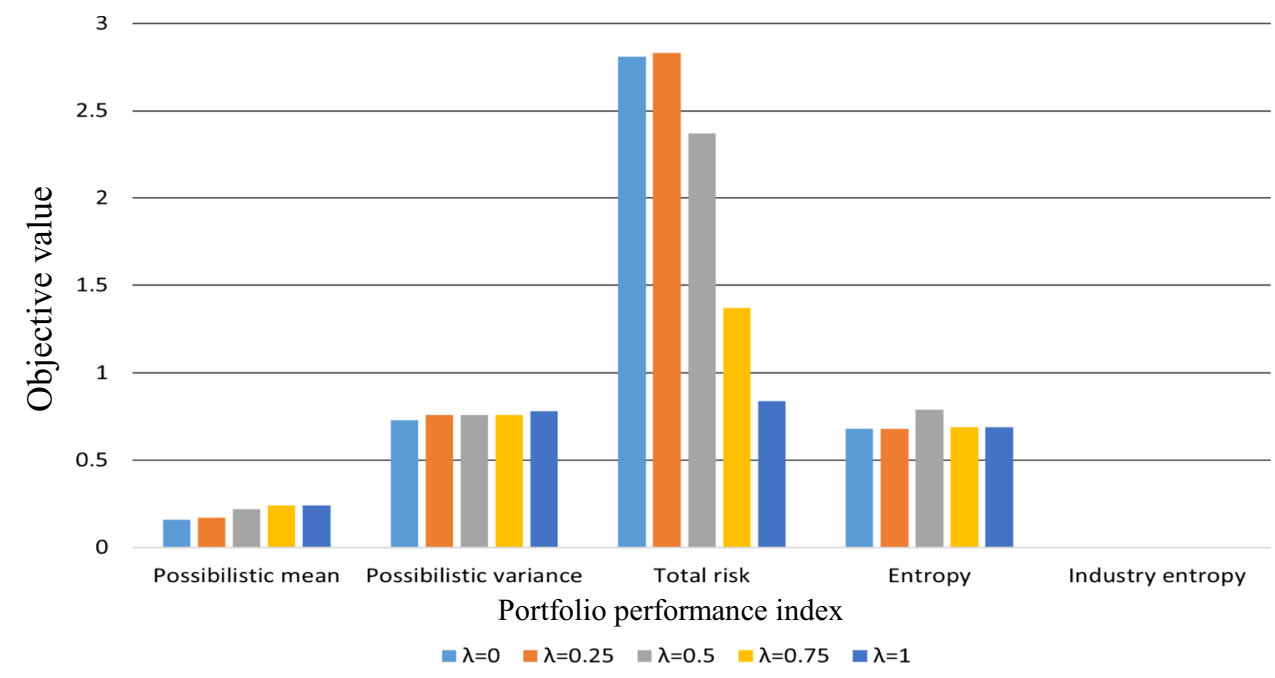

When $\lambda$ takes other values, we can also obtain similar single objective models. Here, we explain the economic significance of $\lambda$. When we deal with the risk objective, we divide the risk into two categories: systematic risk and non- 
Fig. 4 The portfolio performance for optimistic investors when $T=3$

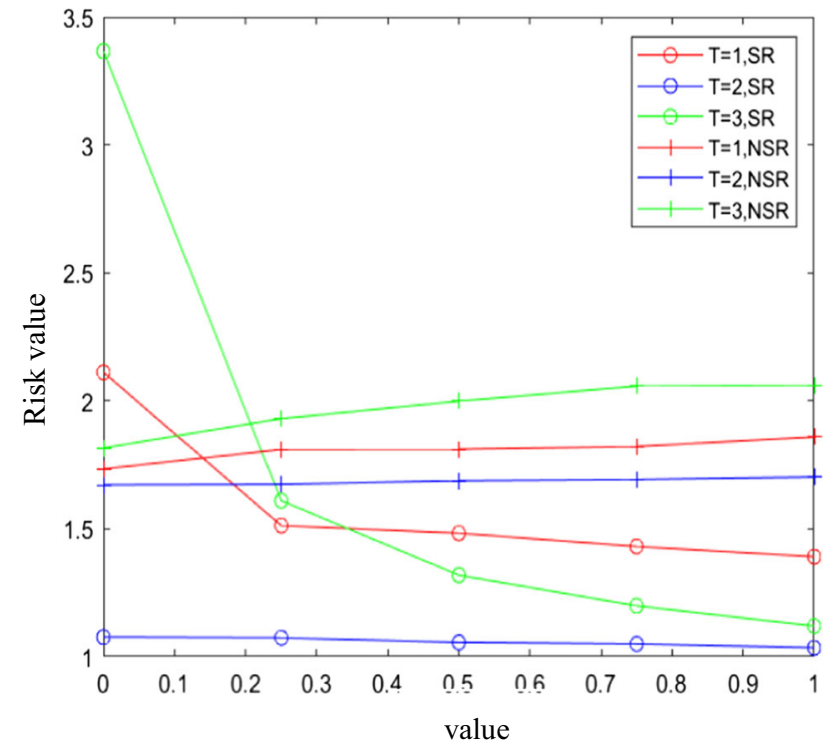

Fig. 5 Comparison about systematic risk and non-systematic risk for optimistic investors

systematic risk. The total risk is obtained by weighting these two kinds of risks, and the weight is set subjectively by investors. $\lambda$ is the weight of coefficient risk, so $\lambda$ can be regarded as the degree of investor's attention to systematic risk.

\subsection{The decision schemes for investors' different psychological attitude}

\subsubsection{The results for optimistic investors}

According to the above section, we will show the investment schemes and the investment performance for optimistic investors with different emphasis on systematic risk in Table 5 and Table 6.

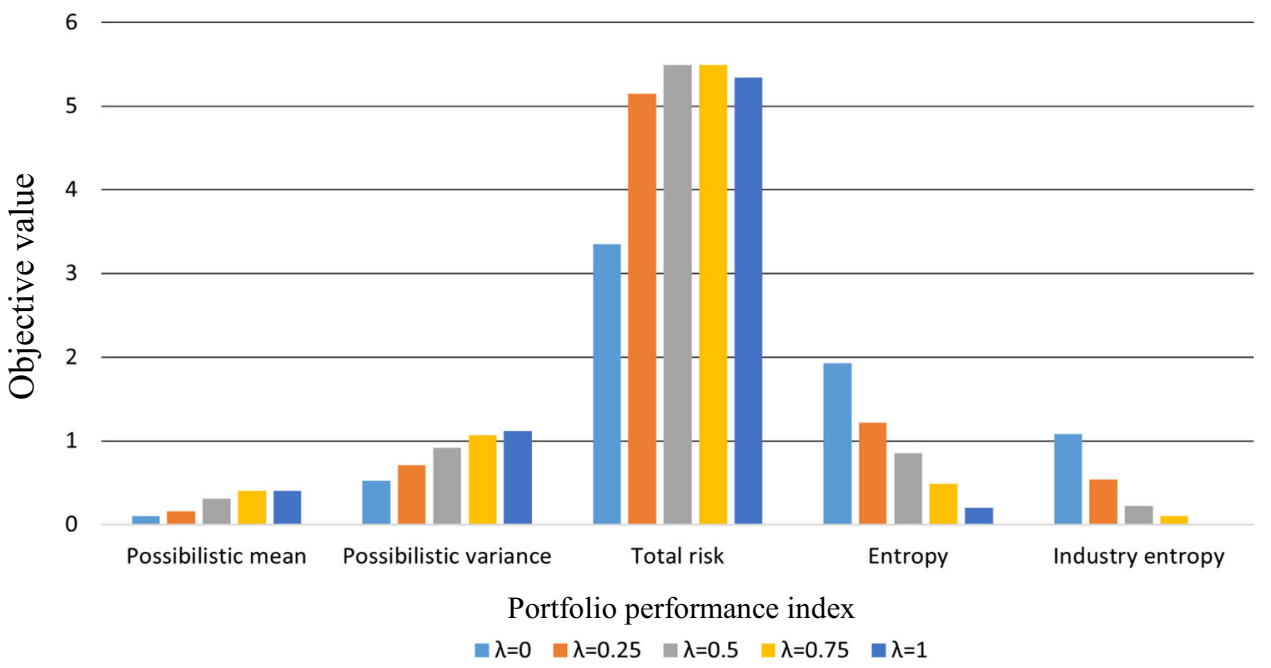

In order to show the results intuitively and compare the results conveniently, we show the results in Figs. 2, 3, 4.

In Fig. 2, we can find that all the performance values reach a relatively high level when $\lambda=0.5$. According to possibilistic mean and the possibilistic variance, we cannot judge that which status performs well. Besides, the total risk reaches the highest level when $\lambda=0.5$. In other words, investors will choose a high-return and high-risk investment scheme when they pay the same attention to systematic risk and non-systematic risk. For entropy and industry entropy, they will take a more diversified investment scheme when $\lambda=0.5$.

In Figs. 3 and 4, we can find that the possibilistic mean and the possibilistic variance of portfolio fuzzy return stay at a relatively lower status. That is because COVID-19 pandemic has brought about huge risks to the financial market. According to entropy and the industry entropy, both values also stay at relatively lower statues. Even with $\lambda$ increasing, the value becomes lower and lower. That means investors invest in some specific securities and industries. In Fig. 3, we can find the industry entropy reaches 0 whatever $\lambda$ is. At that time, investors invest in a specific industry.

In Fig. 5, the $x$-axis represents $\lambda$ value. The $y$-axis represents the risk value. We denote systematic risk as SR and non-systematic risk as NSR. From Fig. 5, we can find that the SR lines present a downward trend and the NSR lines present an upward trend with $\lambda$ value increasing, because the $\lambda$ value shows the investors' emphasis on systematic risk. Besides, the systematic risk value first decreases significantly and then decreases slowly with $\lambda$ value increasing. However, the rising trend of non-systematic risk is relatively even. This means that proper attention to systematic risk can significantly reduce the systematic risk, and increase the non-systematic risk slightly, which makes investors get a satisfactory portfolio. 
Table 7 Portfolio solution for pessimistic investors in models (32)-(34)

Table 8 Portfolio performance for pessimistic investors in models (32)-(34)

Fig. 6 The portfolio performance for pessimistic investors when $T=1$

\begin{tabular}{lllllllllll}
\hline$\lambda$ & $T$ & $S_{1}$ & $S_{2}$ & $S_{3}$ & $S_{4}$ & $S_{5}$ & $S_{6}$ & $S_{7}$ & $S_{8}$ & $S_{9}$ \\
\hline 0.00 & $T=1$ & 0.16 & 0.03 & 0.17 & 0.13 & 0.09 & 0.05 & 0.14 & 0.12 & 0.10 \\
& $T=2$ & 0.11 & 0.13 & 0.11 & 0.04 & 0.27 & 0.06 & 0.07 & 0.13 & 0.06 \\
& $T=3$ & 0.03 & 0.04 & 0.30 & 0.05 & 0.22 & 0.15 & 0.04 & 0.07 & 0.10 \\
0.25 & $T=1$ & 0.01 & 0.04 & 0.01 & 0.08 & 0.01 & 0.01 & 0.41 & $0 . .01$ & 0.43 \\
& $T=2$ & 0.11 & 0.15 & 0.11 & 0.06 & 0.30 & 0.03 & 0.08 & 0.10 & 0.06 \\
0.50 & $T=3$ & 0.03 & 0.01 & 0.00 & 0.53 & 0.00 & 0.38 & 0.04 & 0.00 & 0.00 \\
& $T=1$ & 0.01 & 0.04 & 0.01 & 0.08 & 0.01 & 0.01 & 0.41 & 0.00 & 0.43 \\
& $T=2$ & 0.12 & 0.17 & 0.08 & 0.10 & 0.30 & 0.02 & 0.08 & 0.08 & 0.06 \\
0.75 & $T=3$ & 0.01 & 0.00 & 0.00 & 0.81 & 0.00 & 0.17 & 0.01 & 0.00 & 0.00 \\
& $T=1$ & 0.01 & 0.03 & 0.01 & 0.05 & 0.01 & 0.01 & 0.39 & 0.00 & 0.50 \\
& $T=2$ & 0.12 & 0.17 & 0.06 & 0.16 & 0.29 & 0.01 & 0.08 & 0.06 & 0.06 \\
& $T=3$ & 0.00 & 0.00 & 0.00 & 0.93 & 0.00 & 0.04 & 0.00 & 0.00 & 0.00 \\
& $T=1$ & 0.01 & 0.04 & 0.01 & 0.09 & 0.01 & 0.01 & 0.29 & 0.00 & 0.54 \\
& $T=2$ & 0.12 & 0.18 & 0.04 & 0.23 & 0.26 & 0.01 & 0.07 & 0.04 & 0.06 \\
& $T=3$ & 0.00 & 0.00 & 0.00 & 0.98 & 0.00 & 0.02 & 0.00 & 0.00 & 0.00 \\
\hline
\end{tabular}

\begin{tabular}{lllllll}
\hline$\lambda$ & $T$ & Possibilistic mean & Possibistic variance & Total risk & Entropy & Industry entropy \\
\hline 0.00 & $T=1$ & 0.45 & 0.45 & 3.93 & 2.09 & 1.10 \\
& $T=2$ & 0.15 & 0.70 & 2.78 & 0.72 & 0.31 \\
& $T=3$ & 0.12 & 0.53 & 3.33 & 1.95 & 0.20 \\
0.25 & $T=1$ & 0.65 & 0.59 & 3.23 & 1.56 & 0.98 \\
& $T=2$ & 0.13 & 0.70 & 2.80 & 0.72 & 0.11 \\
& $T=3$ & 0.13 & 0.68 & 5.08 & 1.25 & 0.32 \\
0.50 & $T=1$ & 0.63 & 0.58 & 2.84 & 1.35 & 0.11 \\
& $T=2$ & 0.18 & 0.73 & 2.39 & 0.73 & 0.10 \\
0.75 & $T=3$ & 0.28 & 0.86 & 5.39 & 0.90 & 0.20 \\
& $T=1$ & 0.63 & 0.58 & 2.42 & 1.24 & 0.20 \\
& $T=2$ & 0.20 & 0.73 & 1.30 & 0.60 & 0.10 \\
1.00 & $T=3$ & 0.35 & 1.01 & 5.42 & 0.55 & 0.00 \\
& $T=1$ & 0.65 & 0.60 & 2.38 & 1.40 & 0.63 \\
& $T=2$ & 0.22 & 0.73 & 0.80 & 0.75 & 0.00 \\
& $T=3$ & 0.38 & 1.10 & 5.28 & 0.25 & 0.06 \\
\hline
\end{tabular}

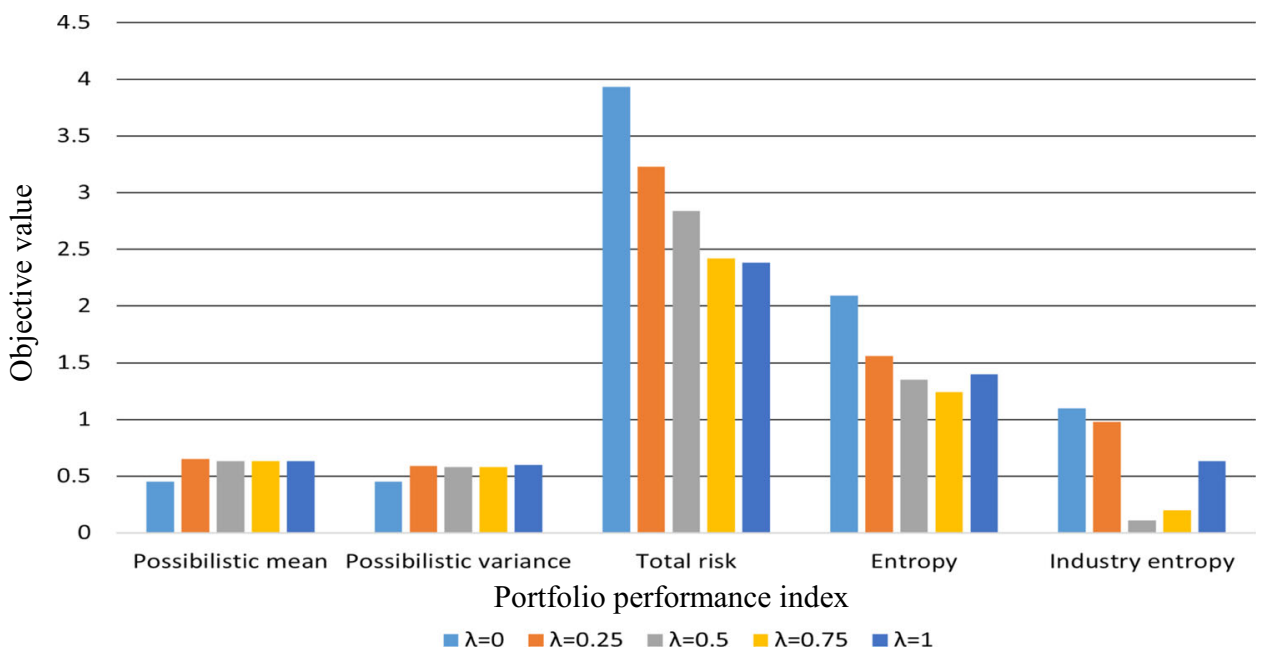


Fig. 7 The portfolio performance for pessimistic investors when $T=2$

Fig. 8 The portfolio performance for pessimistic investors when $T=3$
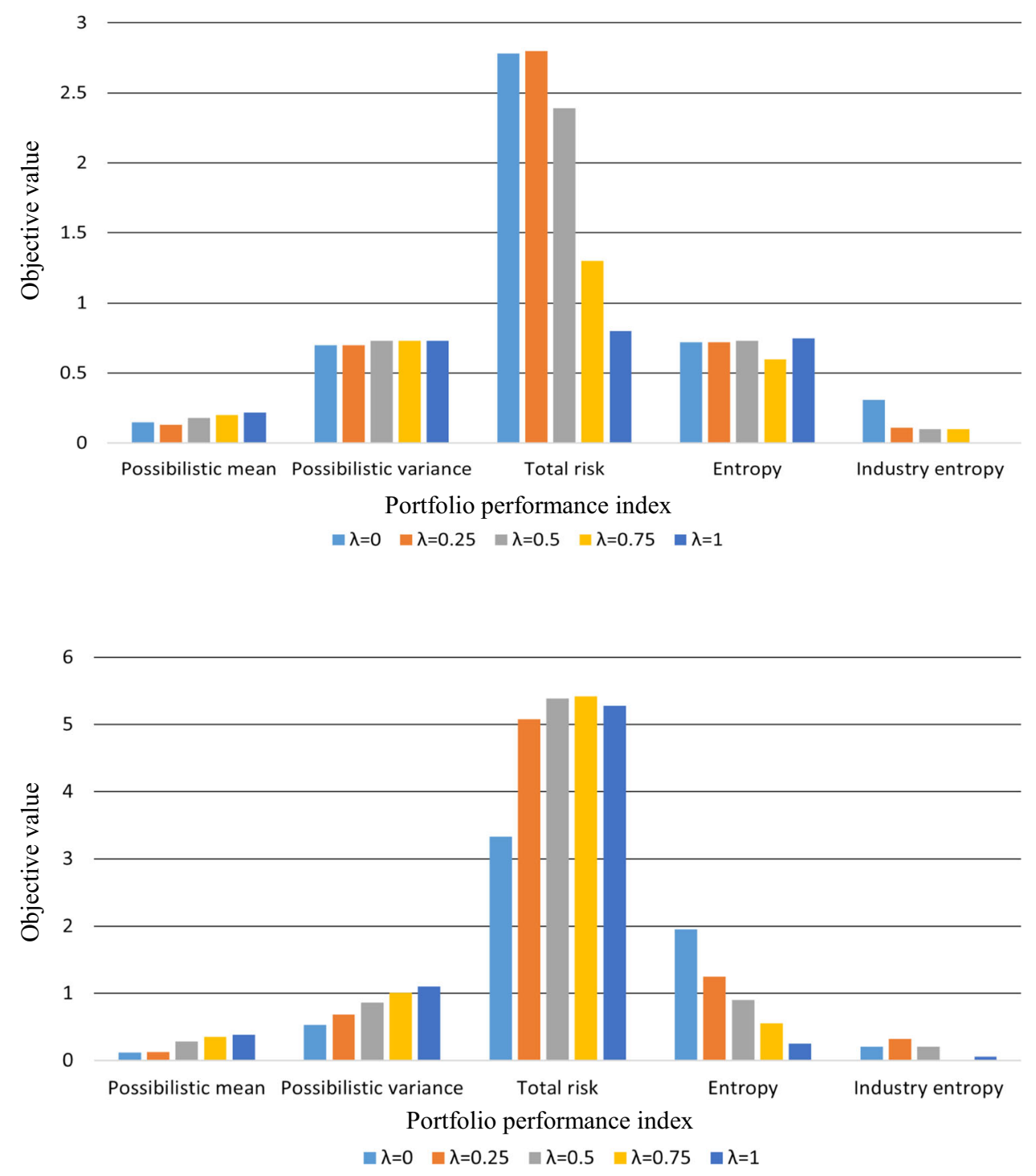

\subsubsection{The results for pessimistic investors}

According to the above section, we can also show the investment schemes and the investment performance for pessimistic investors under different emphasis on systematic risk in Table 7 and Table 8.

In Table 7 and Table 8, conclusions are similar when investors are optimistic. The investment scheme is shown in different emphasis on systematic risk. Firstly, $T=1,2,3$ are three periods which represent the explosive process of COVID-19. $T=1$ means the COVID-19 has not broken out. $T=2$ means the COVID-19 was breaking out. And $T=3$ means that the COVID-19 was stabilized. Then we can analyze the reasons for choosing such an investment scheme from the perspective of empirical analysis. If we don't consider systematic risk, we will adopt diverse investment scheme before the COVID-19 broke out. With the COVID-19 broke out and then stabilizing, investors

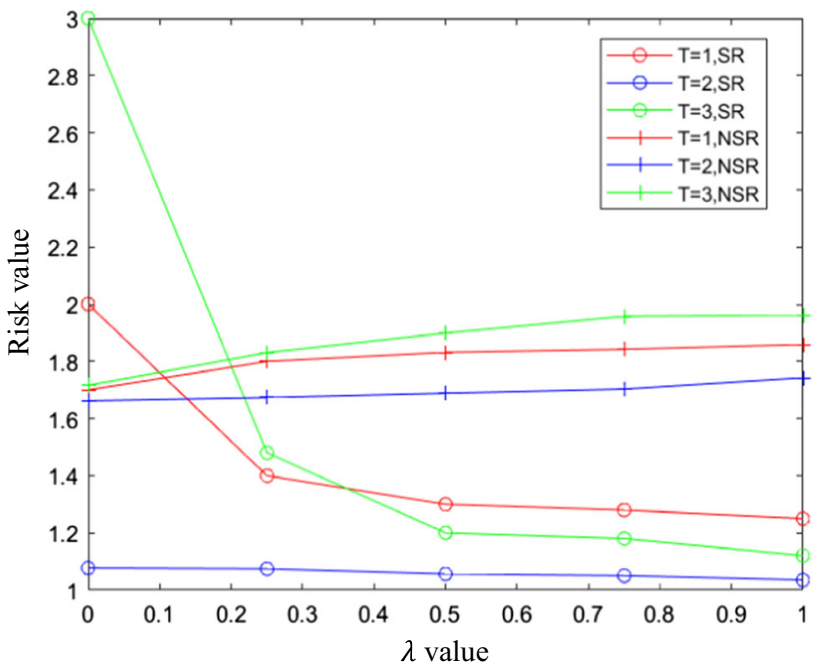

Fig. 9 Comparison about systematic risk and non-systematic risk for pessimistic investors 
prefer to invest in industries like hygiene and pharmaceutical manufacturing. That means industries like fishery face operational difficulties which are caused by the COVID-19 as an external factor. With the $\lambda$ value increasing, the aforesaid phenomenon becomes more obvious. The investment scheme even concentrates in the specific industries whose beta coefficients are relatively lower in that period.

In order to show the results intuitively and compare the results conveniently, we show the results in Figs. 6, 7, 8, 9.

From Fig. 6, it is obvious that the possibilistic mean and the possibilistic variance have no significant change with $\lambda$ increasing. But with $\lambda$ increasing, the total risk decreases significantly. That means the more attention to systematic risk, the less total risk the investors bear. According to entropy and industry entropy, pessimistic investors may pay more attention to portfolio diversification. But with more attention to systematic risk, pessimistic investors prefer to reduce diversity of securities investment but not focus on only one industry.

From Fig. 7, we can find that the possibilistic mean is lower and the possibilistic variance is higher compared with the period $T=1$. That means the COVID-19 brought serious influence on the securities market. Additionally, the total risk decreases with $\lambda$ value increasing similarly. This once again explains that attaching importance to systematic risk can reduce the total investment risk. According to entropy and industry, pessimistic investors allocate their money to various securities in different industries. That is because the entropy value is relatively higher, but the industry entropy is relatively lower.

From Fig. 8, it is easy to obtain that both the possibilistic mean and the possibilistic variance increase with $\lambda$ value increasing. That means pessimistic investors prefer more to their return status when they pay more attention to systematic risk. For total risk, a trend where the total risk increases and then decreases is presented. That means proper attention to systematic risk will increase the total risk. According to entropy and industry entropy, pessimistic investors will reduce their investment diversification with $\lambda$ value increasing. That may be because they want to invest in some lower risk securities.

In Fig. 9, there exist the similar phenomena compared with Fig. 5. We denote systematic risk as SR and nonsystematic risk as NSR. From Fig. 9, we can find that the SR lines present a downward trend and the NSR lines present an upward trend with $\lambda$ value increasing, because the $\lambda$ value shows the investors' emphasis on systematic risk. Besides, the systematic risk value first decreases significantly and then decreases slowly with $\lambda$ value increasing. However, the rising trend of non-systematic risk is relatively even. This means that proper attention to systematic risk can significantly reduce the system risk and increase the non-systematic risk slightly, which makes investors get a satisfactory portfolio.

\subsubsection{Some comprehensive analysis to three objective values}

According to the aforesaid phenomenon, we can draw some conclusions from the fuzzy return status, total risk and entropy.

(a) For fuzzy return status. As $\lambda$ value increases, the possibilistic mean increases significant with the possibilistic variance increasing slightly. But when $\lambda$ increases to a relatively higher value, the possibilistic mean cannot be improve and the possibilistic variance worsens on the contrary. That means proper attention to system risk can improve the risk status.

(b) For total risk. It is mentioned that the total risk presents a trend of first increasing and then decreasing with $\lambda$ value increasing if we don't consider any other objectives. But from Table 6 , the similar regular is presented for the total risk. That means whatever objectives we consider, once we pay more or pay less attention to systematic risk, the portfolio risk will be underestimated.

(c) For investment diversification degree. Before the COVID-19, the value of entropy and industry entropy are relatively higher, which means that investors abide by the principle of diversification investment. Since the outbreak of the pandemic, the entropy decreases and the industry entropy decreases to 0 . That means investors transfer their capital to a specific industry which faces the lowest risk brought about by the COVID-19. When the COVID-19 situation becomes stabilized, investors start to diversify their capital to different industries again. But in general, the entropy will decrease with $\lambda$ value increasing.

In a word, in the above discussion, it is important to pay proper attention to systematic risk. It will improve our fuzzy return status, effectively evaluate the total risk and have no conflict with diversification investment. Paying too little or too much attention to systematic risk both will lead to a portfolio whose risk and return mismatch. And the latter even makes investors invest only one industry. Once the industry is hit, perhaps investors will bear a huge loss if they don't withdraw investment. 


\section{Conclusion}

In this paper, a hybrid multi-objective portfolio model is constructed, which considers fuzzy return status, systematic risk, non-systematic risk and entropy. To solve our proposed model, novel fuzzy dominant goal programming is put forward firstly. It can be used to search for a dominant fuzzy return status according to investors' attitude and convert the model to traditional multi-objective model which can be solved by classical goal programming. Finally, properly emphasis on systematic risk can optimize the investment scheme by a numerical example.

In essence, portfolio selection is a multi-objective decision-making problem. In this paper, the goal programming based on Fuzzy dominance is a method to deal with uncertainty in multi-objective problems. However, in real life, there are many multi-objective decision-making problems. For example, Su and Xu (2019) applied the fuzzy comprehensive evaluation method to build an evaluation model and calculated the evaluation weight of each level index. By the calculation of membership degree matrix, the overall score of the high-speed rail express branch is determined. Chen et al. (2021) proposed an integrated subjective-objective approach to calculate criterion weights and to implement an ELECTRE III-based method that incorporates HFLTS possibility distributions, which allows us to treat the indetermination, imprecision and uncertainty embedded in appraisals of alternative-criterion decisions when evaluating bids. Mirzaee et al. (2018) generalized the problem of supplier selection and order allocation with multi-period, multi-product, multisupplier, multi-objective cases as well as quantity discount subject to budget and capacity limitations for both buyers and suppliers. They solved the model by a preemptive fuzzy goal programming approach. The fuzzy membership function tactic based on goal programming to obtain the desired compromise solution of a multi-objective transportation problem (MOTP) in uncertain environment is proposed by Uddin et al. (2021) where the DM can choose a confidence level for different parameters. We believe that a satisfactory objective status for the decision making involving uncertain can basically be found by using the method of fuzzy goal programming.

In the further study about portfolio and goal programming, we will continue do the following. Firstly, we can consider investing in a frictional financial market. Secondly, in dealing with returns, other uncertain theory can be adopted to measure returns. Finally, we can continue to study goal programming and develop it from the angle of uncertain programming.

Acknowledgements This research was supported by the "Humanities and Social Sciences Research and Planning Fund of the Ministry of
Education of China, No. 18YJAZH014-x21xY9180090," "Natural Science Foundation of Guangdong Province, No. 2019A1515011038," "Soft Science of Guangdong Province, No. 2018A070712006, 2019A101002118" and "Guangdong Province Characteristic Innovation Project of Colleges and Universities, No. 2019GKTSCX023." The authors are highly grateful to the referees and editor in-chief for their very helpful comments.

Author contributions Xue Deng was responsible for the overall understanding of the structure of the article, the main idea of the article, the conclusion analysis of the article and the revision of the full text. Yongkang Yuan performed the data analyses and wrote the manuscript.

\section{Declarations}

Conflict of interest We declare that we have no conflict of interest.

Ethical approval This article does not contain any studies with human participants or animals performed by any of the authors.

Informed consent Informed consent was obtained from all individual participants included in the study.

\section{References}

Aouni B, Colapinto C, La Torre D (2014) Financial Portfolio management through the goal programming model: current state-of-the-art. Eur J Oper Res 234:536-545

Brandtner M, Kürsten W, Rischau R (2020) Beyond expected utility: Subjective risk aversion and optimal portfolio choice under convex shortfall risk measures. Eur J Oper Res 285:1114-1126

Carlsson C, Fullér R (2001) On Possibilistic mean value and variance of fuzzy numbers. Fuzzy Sets Syst 122:315-326

Chen Q, Gerlach H (2013) The two-sided Weibull distribution and forecasting financial tail risk. Int J Forecast 29:527-540

Chen ZS, Chin KS, Li Y-L (2016) A framework for triangular fuzzy random multiple-criteria decision making. Int J Fuzzy Syst $18: 227-247$

Chen ZS, Zhang X, Rodriguez RM, Pedrycz W, Martinez L (2021) Expertise-based bid evaluation for construction-contractor selection with generalized comparative linguistic ELECTRE III. Autom in Constr 125

Cheng P, Wolverton ML (2001) MPT and the downside risk framework: a comment on two recent studies. Real Estate Portf Manag 7:125-131

Dubois D, Prade H (1988) Possibility theory. Plenum Press, New York, pp 1-10

Farhad H, Nemati H, Sun MH (2013) Robust optimization for multiobjective programming problems with imprecise information. Procedia Comput Sci 17:357-364

Gao JW, Guo GJ, Ma ZY, Huang X (2021) Multi-criteria decisionmaking framework for large-scale rooftop photovoltaic project site selection based on intuitionistic fuzzy sets. Appl Soft Comput 102:98-107

Gupta P, Mehlawat MK, Yadav S, Kumar A (2019) A polynomial goal programming approach for intuitionistic fuzzy portfolio optimization using entropy and higher moments. Appl Soft Comput J 85:185-192

Hao FF, Liu YK, Wang S (2008) The variance formulas for triangular fuzzy random variables. Int Conf Mach Learn Cybern IEEE $1: 612-617$ 
Hose D, Hanss M (2021) A universal approach to imprecise probabilities in possibility theory. Int $\mathrm{J}$ Approx Reason 133:133-158

Huang XX (2007) A new perspective for optimal portfolio selection with random fuzzy returns. Inf Sci 177:405-414

Huang XX (2008) Mean-entropy models for fuzzy portfolio selection. IEEE Trans Fuzzy Syst 16:1096-1101

Li J, Xu JP (2013) Multi-objective portfolio selection model with fuzzy random returns and a compromise approach-based genetic algorithm. Inf Sci. Inf Sci 220:207-521

Liagkouras K, Metaxiotis K (2018) Multi-period mean-variance fuzzy portfolio optimization model with transaction costs. Eng Appl Artif Intell 67:260-269

Liesiö J, Peng X, Kuosmanen T (2020) Portfolio diversification based on stochastic dominance under incomplete probability information. Eur J Oper Res 286:755-768

Lv YQ, Zhou QW, Li YF, Li WD (2021) A predictive maintenance system for multi-granularity faults based on AdaBelief-BP neural network and fuzzy decision making. Adv Eng Inf 49

Markowitz H (1952) Portfolio selection. J Finance 7:77-91

Mehmet A, Osman P (2018) A polynomial goal programming model for portfolio optimization based on entropy and higher moments. Expert Syst Appl 94:185-192

Meng FY, Tang J, Pedrycz WT (2021) Dual hesitant fuzzy decision making in optimization models. Comput Ind Eng 154:103-107

Mirzaee H, Naderi B, Pasandideh SHR (2018) A preemptive fuzzy goal programming model for generalized supplier selection and order allocation with incremental discount. Comput Ind Eng 122:292-302

Philippatos GC, Wilson CJ (1972) Entropy, market risk, and the selection of efficient portfolios. Appl Econ 4:209-220

Qin ZF (2017) Random fuzzy mean-absolute deviation models for portfolio optimization problem with hybrid uncertainty. Appl Soft Comput 56:597-603

Sadati H, Nematian J (2013) Two-level linear programming for fuzzy random portfolio optimization through possibility and necessitybased model. Procedia Econ Finance 5:657-666
Sak H, Başoğlu I (2017) Efficient randomized quasi-Monte Carlo methods for portfolio market risk. Insurance Math Econ 76:87-94

Shannon CE (1948) A mathematical theory of communication. Bell Syst Tech J 27:397-423

Shen Y (2015) Mean-variance portfolio selection in a complete market with unbounded random coefficients. Automatica $55: 165-175$

Soumik P (2019) Exponentially concave functions and high dimensional stochastic portfolio theory. Stoch Process Appl 129:3116-3128

Su YT, Xu L (2019) High-speed rail express service quality based on fuzzy comprehensive evaluation. In: Proceedings of the 6th international conference on transportation engineering, pp 662-670

Tanaka H, Guo P (1999) Portfolio selection based on upper and lower exponential possibility distributions. Eur J Oper Res 114:115-126

Uddin MS, Miah M, Khan MA, Alarjani A (2021) Goal programming tactic for uncertain multi-objective transportation problem using fuzzy linear membership function. Alex Eng J 60:2525-2533

Vercher E, Bermudez JD (2013) A possibilistic mean-downside riskskewness model for efficient portfolio selection. IEEE Trans Fuzzy Syst 21:585-595

Wang ZJ (2018) A goal programming approach to deriving interval weights in analytic form from interval Fuzzy preference relations based on multiplicative consistency. Inf Sci 462:160-181

Watada J (1997) Fuzzy portfolio selection and its applications to decision making. Tatra Mt Math Publ 13:219-248

Xu JP, Zhou XY, Wu DD (2011) Portfolio selection using mean and hybrid entropy. Ann Oper Res 185:213-229

Zadeh LA (1965) Fuzzy sets. Inf Control 8:338-353

Zadeh LA (1978) Fuzzy sets as a basis for a theory of possibility. Fuzzy Sets Syst 1:3-28

Publisher's Note Springer Nature remains neutral with regard to jurisdictional claims in published maps and institutional affiliations. 